\title{
Studies on fatigue crack growth for airframe structural integrity applications
}

\author{
R SUNDER \\ Structural Integrity Division, National Aerospace Laboratories, Bangalore \\ 560017, India \\ Present address: Bangalore Integrated System Solutions, 99, 14th A cross, \\ Malleswaram, Bangalore 560003, India
}

\begin{abstract}
A review is made of efforts at the National Aerospace Laboratories in the development of fatigue crack growth prediction technology for airframe applications. The research was focused on extension of rainflow techniques for crack growth analysis and development of accelerated crack growth calculation methods for spectrum loading. Fatigue crack closure forms a crucial element of modelling and fractographic techniques were developed for its study. These, combined with binary coded event registration enabled crack growth and closure mapping for part-through cracks in metallic materials. Experimental research on short cracks at notches led to discovery of the hysteretic nature of crack closure, which explains wellknown history-sensitive local mean stress effects in notch root fatigue. Optical fractography of failures obtained under simulated service conditions revealed that short cracks do not exhibit any more scatter than long cracks at comparable growth rates. The nature of multi-site crack initiation and growth of small cracks at notches was investigated and the effort extended to lug joints that are widely used in airframe applications. Results from this work suggest the possibility of modelling crack growth from a size smaller than 50 microns through to failure, thereby accounting for a major fraction of total life.
\end{abstract}

Keywords. Fatigue crack growth; rainflow technique; airframe structural integrity; fractographic techniques.

\section{Introduction}

For many years $S$ - $N$ (stress-life) curves served as the major input in design to meet endurance requirements. The curves were established from experimental data obtained predominantly on rotating cantilever machines. These work-horses of early experimental research on metal fatigue were essentially restricted in application to constant amplitude high cycle fatigue. While the application value of such data is considerable in the case of some engineering components including axles and weldments in reversed 
bending, the appearance of high performance structures such as airframes and automobilies imposed new requirements. The service load environment of many fatigue critical structures is often characterized by a mix of an extremely large number of small load cycles, which can cause the bulk of damage and a few overloads that can induce inelastic response and associated stress-strain hysteresis and residual stresses. The combination of Miner's rule (Miner 1945) and $S-N$ curves can fail to account for the complex nature of fatigue damage under such conditions.

The advent of servohydraulic test technology and computer control introduced the capability to test materials and components under conditions that closely relate to actual service environment. The concept of servo feedback control inade it possible to use displacement transducers for testing under axial strain control-an essential requirement to determine the relationship between strain amplitude and fatigue life in Low-Cycle Fatigue (LCF). Computer control made incremental strain testing easy making it possible to determine the cyclic stress-strain curve from a single test. This curve is essential if one is to calculate fatigue life for a notched component under service loading. Finally, computer control also made it possible to validate life predictions through testing under simulated service load sequences. This was the framework for JoDean Morrow's pioneering work (Morrow 1968) on the notch root mean stress effect in LCF and the subsequent development of the Manson-Coffin-Smith-WatsonTopper relationships for fatigue life (Manson et al 1966; Topper et al 1970). Wetzel's modelling of the Masing relationship (Wetzel 1971), combined with the Neuber equation (Neuber 1961) relating applied elastic stress excursions to notch root inelastic stress-strain response provided the analytical foundation for extension of laboratory data obtained on smooth coupons in LCF to notched components under service loading (Dowling et al 1977). Today's industry standard procedures for fatigue analysis are based on these inputs: general engineering design for endurance including automotive design applications rely on fatigue analysis using the local stress-strain approach (LSS).

\section{Why is fatigue crack propagation significant in fatigue analysis?}

It has been long recognized that fatigue crack growth is the final stage leading to failure of the material through gradual and irreversible reduction in residual strength. The fraction of total fatigue life exhausted on crack propagation (FCP life) is known to depend on a number of variables (Schijve 1967). The assumed initial crack length plays an obvious role - if crack growth is tracked from a smaller crack length, one would account for a larger FCP life interval. High strength materials as a rule show a smaller fraction of FCP life as opposed to high toughness materials - while the former may be highly resistant to crack initiation, once a crack is formed, failure follows early. Briefly, this dichotomy is related to ductility: a given alloy system will exhibit reduction in ductility with increase in yield and ultimate strength; crack initiation life reduces with increased cyclic inelastic strain (irreversible slip-band formation is accelerated), while conversely, crack growth is restrained by the formation of a large plastic zone (whose size increases with reduced yield stress). This enhances resistance to fracture in two ways: energy dissipation occurs over a larger volume of material (Raju 1980) and crack tip blunting associated with local yield reduces local stress concentration (Christensen 1959). With increase in stress level, a larger fraction of total life is spent on FCP (when viewed from a given initial crack length to failure). In fact, recent studies on short crack 
growth at notches revealed that crack growth at high stress level can commence without any incubation period (Newman et al 1992; Prakash et al 1994).

As finite geometry affects critical crack size, a large structural component will permit a larger crack than a smaller component, particularly in a thin section promoting plane-stress conditions with a propotional increase in critical crack size. It would follow that in many large built-ıp, thin-walled structures like airframes, a crack may initiate early at a stress raiser under conditions of plane strain, then propagate into a through crack that may grow for a substantial time, particularly if local stiffeners inhibit rapid increase of stress intensity with crack length (Poe 1971). One may note that airframe design requirements recommend the implementation of multiple-load path configuration, which in a deformation controlled situation will always lead to stress relaxation in a cracked element. $S$ - $N$ curves obtained on small round coupons are unlikely to provide useful inputs for estimating the endurance of such structural components.

Operational environment provides compelling reasons to address endurance from a crack growth viewpoint. Current accent in technology development is on the ability to monitor the condition of a structure in service. New design standards call for repair, overhaul and eventual retirement for cause, rather than on the basis of calendar years or hours of service. There is no practical way to track exhaustion of life to crack initiation. Indeed, there is no parameter that can be said to represent damage in the stage of crack initiation. The one exception to this rule may be the observation that residual compressive stresses induced as part of the manufacturing process tends to relax prior to crack initiation. Crack size on the other hand serves as a direct indication of damage. By defining an inspection interval based on conservative estimates of FCP life to failure and after defining initial crack size based on inspection capability, modern airframes are operated safely for over thirty calendar years or 60 to 120 thousand hours of useful service.

The origin of design, operation and retirement based on assessment of residual strength in the presence of cracks goes back to the sixties. The United States Air Force which happens to be the world's largest operator of aircraft was the first to recognize the significance of residual strength and life in the presence of cracks. Plagued by a series of catastrophic wing failures on B-47 aircraft in 1958, a programme was initiated to formulate new design standards for airframes (Lincoln 1994). Within ten years, MilSpec 1651A was evolved as the "USAF Aircraft Structural Integrity Program" (ASIP). This standard relies on fracture mechanics criteria for design purposes and is widely used in contemporary aircraft design. The success of ASIP has led to the evolution of similar standards for aeroeıgines (ENSIP).

The past 30 years have seen many advances in understanding the mechanics and mechanisms of fatigue crack growth. Over this period, the discipline of Fracture Mechanics has developed with analytical and numerical tools that handle cracks of virtually any size and shape in both isotropic as well as anisotropic materials including composites and ceramics. The appearance of Transmission and Scanning Electron Microscopy (TEM and SEM) together with computer-controlled servohydraulic load frames contributed greatly to better understanding of mechanisms that control the growth of a fatigue crack under both simpie as well as complex load sequences.

This paper is an attempt to review research effort on FCP at National Aerospace Laboratories (NAL) over the past 15 years in a few selected areas which appear to be of practical significance: 
- Nature of cumulative fatigue damage in FCP under random loading, representative of service conditions, including the contribution of individual cycles to overall fatigue damage,

- Phenomenon of fatigue crack closure, which effectively renders a fatigue crack closed even under tensile loading and is responsible for stress ratio effects and also for lead interaction effects, and,

- Growth of small, part-through cracks at notches that occupies a sizable portionof total fatigue life.

\section{Rainflow cycle counting in cumulative fatigue damange analysis}

Laboratory test data to characterize material resistance to fatigue are obtained under constant amplitude loading. Service load environment on the other hand is random in nature. Fatigue analysis for an arbitrary load sequence is complicated by the absence of complete fatigue cycles that characterized laboratory test conditions during data generation, thereby violating an important similarity criterion. Consider the sequence of loads shown in figure 1 along with the simulated notch root inelastic stress-strain response. We find that the small load excursions $1-3,5-7$ and 10-12 constitute closed fatigue cycles - as indicated by the closed hysteresis loops in the stress-strain plot. Fatigue damage for these cycles can be computed both in terms of exhaustion of fatigue life in crack initiation and in terms of crack extension using available expressions based on laboratory test data for constant amplitude loading. While these cycles are of the same applied magnitude, the stress-strain simulation clearly indicates different local mean stress for each of these cycles due to the effect of superposed overload and underload. Local stress/strain amplitude however will always be identical and load history insensitive, given a stable and symmetric cyclic stress strain curve. In the event notch response would have been totally elastic, local mean stress due to the three cycles would also be identical and load history insensitive. Let us now consider excursions 3-5 and 8-10. While they appear to be complete fatigue cycles when viewed as applied load, clearly, the associated

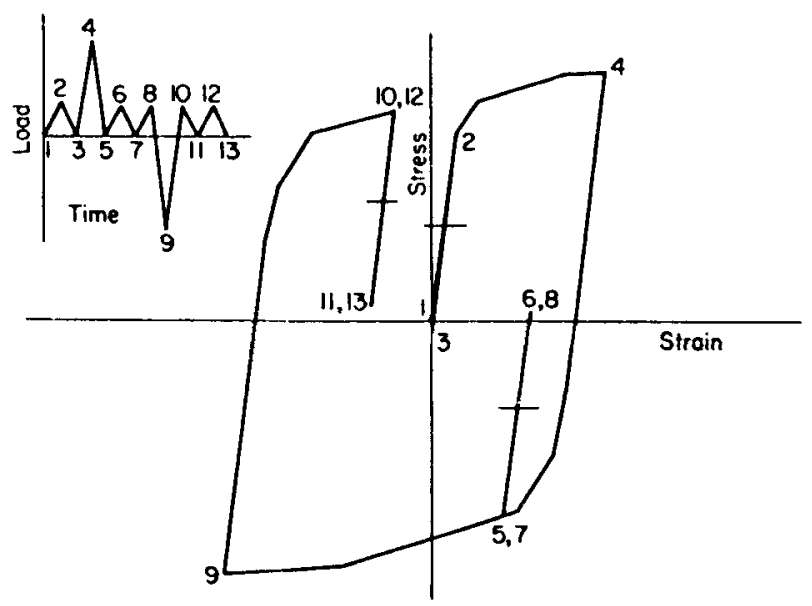

Figure 1. Arbitrary sequence of loads and simulated notch root stress-strain. 
Fatigue crack growth prediction for airframe applications
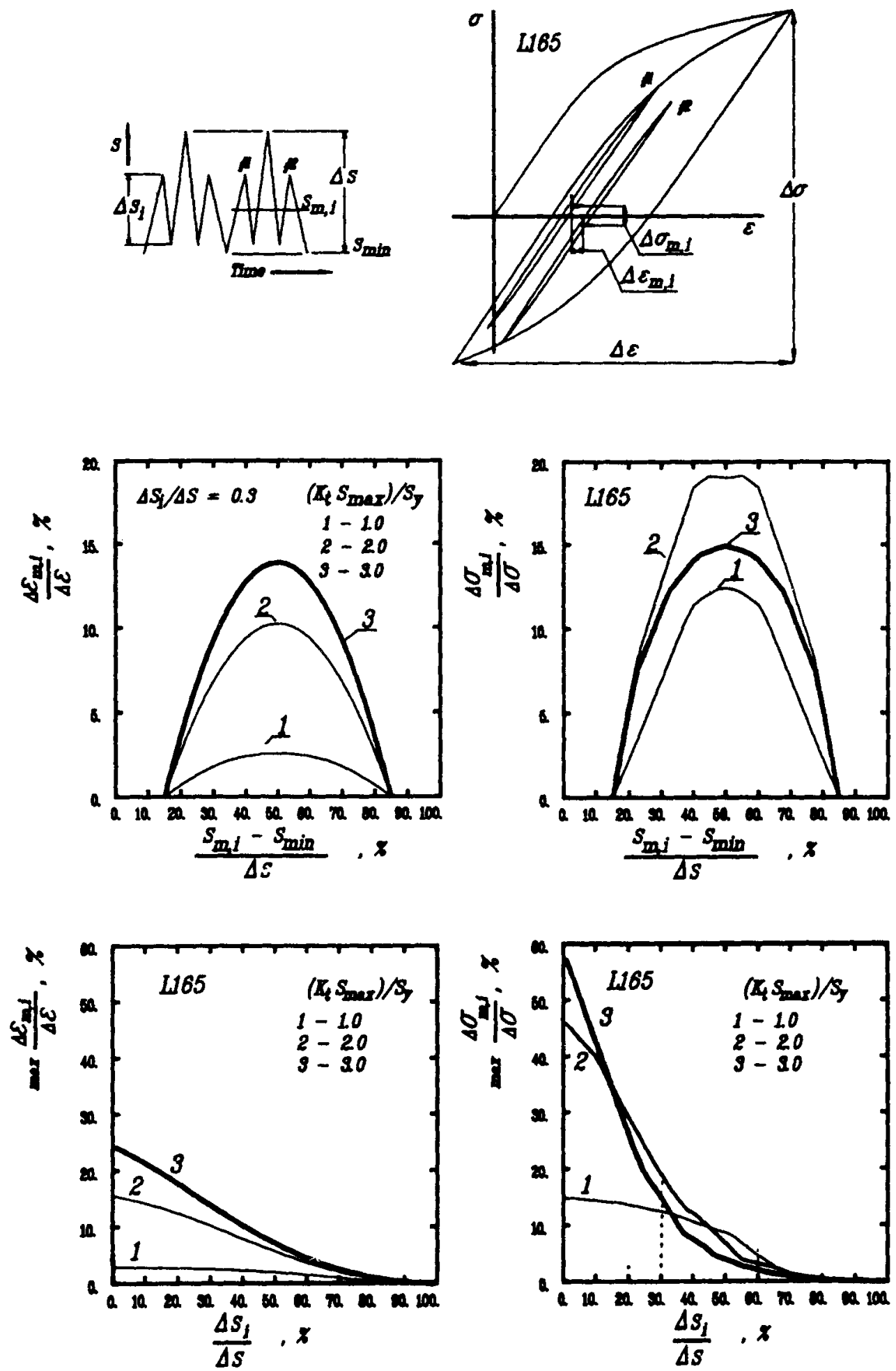

Figure 2. Effect of minor stress range and stress ratio on envelop of notch root mean stress variation (Sunder et al 1984). 
stress-strain excursions indicate they are not. Obviously, one cannot compute fatigue damage for these load excursions. However, should there be one more load excursion starting from 13 and meeting or crossing the load level at 4, the hysteresis loop spanning the points 9 and 4 would close, permitting damage estimates due to the load cycle 4-9-4.

The association of closed stress-strain hysteresis loops with closed fatigue cycles forms the basis for the rainflow cycle counting method invented by Endo (Endo et al 1967). It provides the framework for extending constant amplitude test data to random service load sequences by reducing any given arbitrary load sequence into a table of closed fatigue cycles. ASTM Standard E-1049-85 incorporates rainflow as a recommended procedure for analysis of arbitrary load-time histories.

The rainflow method is essentially based on LCF/LSS concepts. It may be noted that given stable cyclic stress-strain properties and absence of creep, rainflow counted cycles will be notch response insensitive. For this reason, cycle counting performed even on a nondimensionalised load sequence will be valid. As shown in figure 1, the notch root stress and strain amplitude corresponding to counted applied load cycles can be directly computed through Neuber analysis, without recourse to cycle-by-cycle simulation of notch root stress-strain response. Further, Dowling \& Khosrovaneh (1989) have shown that history-dependent variation in local mean stress-strain will occur within a pre-defined envelope that is controlled by the largest load cycle in a given sequence. Another study showed, that the extent of this variation for individual cycles in the rainflow table will be inversely proportional to their amplitude - small cycles will see greater history dependence than large cycles (see figure 2) (Sunder 1992). It follows, that given a rainflow table, upper and lower bound fatigue life can be determined wihout recourse to cycle-by-cycle simulation of notch root stress-strain. For many spectra of practical interest, fatigue life estimates can be accelerated without losing the effect of load history. This illustrates the potential of the rainflow method in 'digesting' complex load histories.

\section{Validity of rainflow for crack growth analysis}

The nature of fatigue damage accumulation by way of fatigue crack extension is not analogous to notch root damage accumulation as handled by the LCF/LSS approach. Therefore, the concept of rainflow cycle counting cannot be automatically extended to fracture mechanics handling of fatigue crack growth. The fatigue crack tip moves as the crack extends. It leaves behind a wake that causes crack ciosure (a detailed consideration of the closure phenomenon is forthcoming), effectively truncating the applied load sequence below a certain level. Finally, crack extension is assumed to occur only in the rising portion of a load cycle, while notch roct reversed slip accumulation occurs equally on both the rising as well as falling half of an applied load cycle.

An experimental study was performed at NAL to examine the validity of rainflow for crack growth analysis (Sunder et al 1984). Typical results appear in figure 3. Figure 3a shows one of the load sequences used in the study. It consists of a number of small cycles embedded within a large cycle on the rising half (segment A) and falling half (segment B). When rainflow counted, segments $A$ and $B$ are identical (though when viewed as rising excursions only, the two are very different). Further, the rainflow counted cycles in the two segments are applied as separate blocks of cycles (segments C and D). As 
shown by the fractograph in figure $3 \mathrm{~b}$, each of these segments leaves behind a discernible striation whose quantitative analysis in figure $3 \mathrm{c}$ and $3 \mathrm{~d}$ clearly demonstrates that:

- segments A and B result in identical crack extension, and,

- crack extension from individual counted cycles in a segment adds up to match the overall crack extension in the segment

In contrast, conventional crack growth computation on the premise that the crack grows during any rising load interval (rainflow is neglected) would have indicated that:
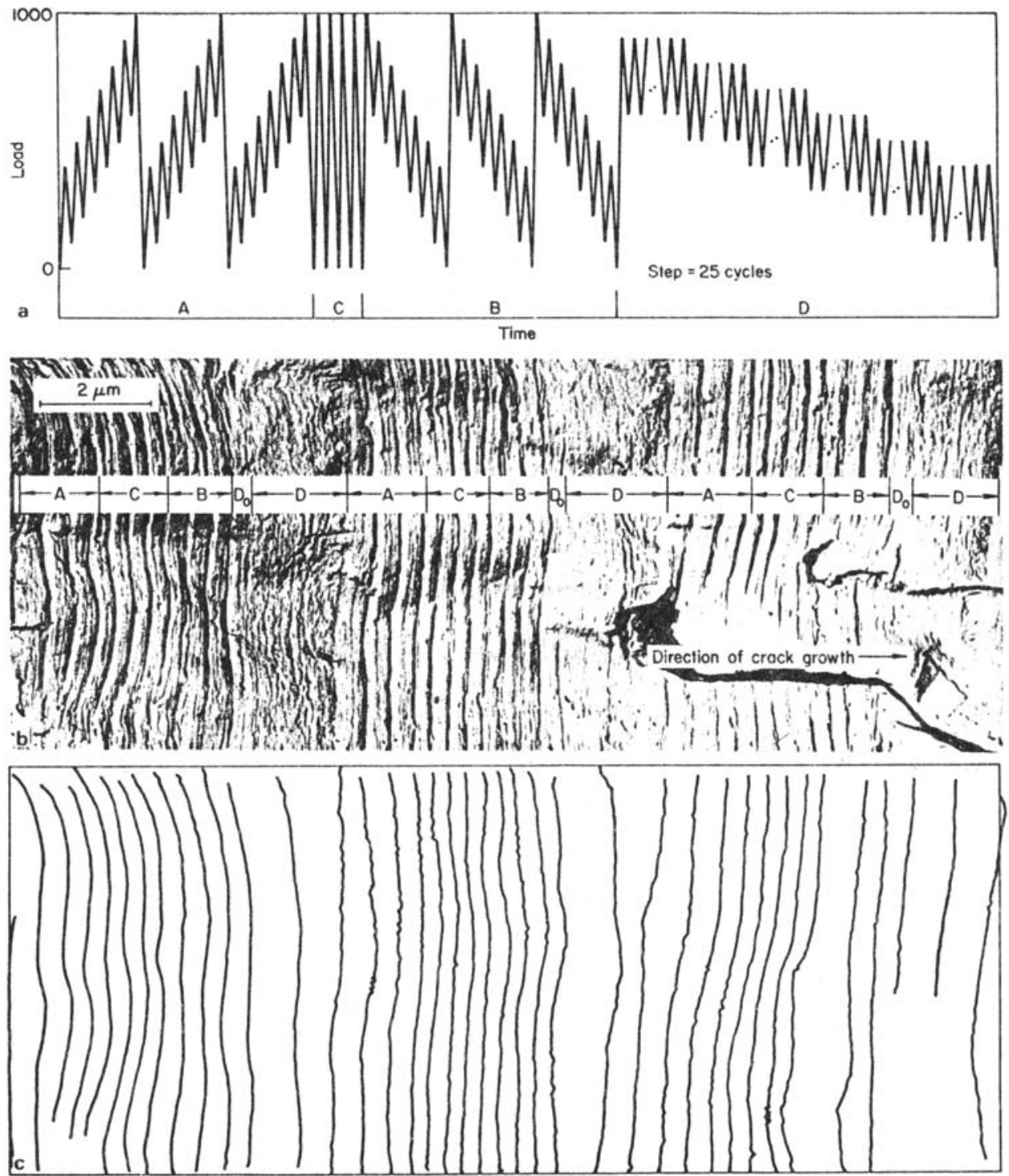

Figure 3. (Continued) 


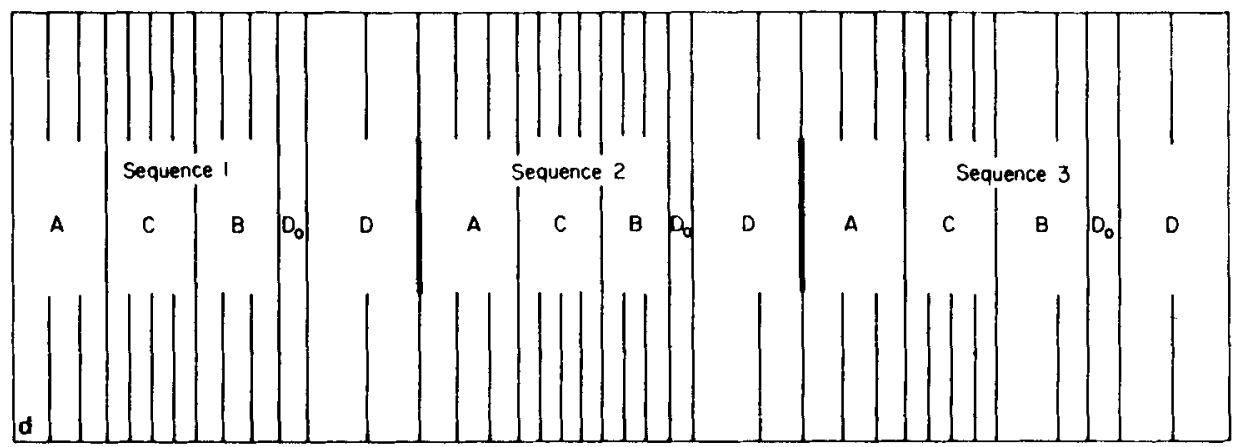

Figure 3. Typical results from fractographic validation of cycle counting techniques (Sunder et al 1984). (a) One block of load sequence. This sequence was repeated to failure. (b) Typical fractograph, showing crack extension in individual segments of load sequence. Repetition of segments removes ambiguity in striation measurement. (c) Digitized fractograph and (d) Equivalent fractograph for quantification of striation spacing which correlate with estimates from rainflow cycle counting.

- crack extension in B will be greater than in A, and,

- cumulative crack extension from individual Rainflow counted cycles will be greater than estimates for A and B based on rising load excursions.

Thus, fractographic evidence appears to back up the validity of rainflow cycle counting for fracture mechanics analysis. A similar conclusion would follow if fatigue crack growth is viewed from energy balance considerations (Raju 1980). Figure 4 shows a schematic of crack tip response to cyclic loading, with the associated stress-strain hysteresis loops. Note that the effect of fatigue crack closure is also shown. It was pointed out earlier, that for rainflow on the applied load sequence to be valid for notch root inelastic stress-strain, the cyclic stress-strain curve has to be stable. In a similar fashion, for rainflow analysis on applied load sequence to be valid for the associated stress-intensity sequence, crack extension over the sequence should be negligible when compared to crack tip plastic zone size. This condition may not be satisfied at higher growth rates, particularly under transport aircraft spectrum loading (Sunder et al 1984). The restriction is illustrated by figure 5 with a schematic of loads in a full flight (ground-air-ground cycle). The overload seen in the middle of the flight will close into a full rainflow counted cycle only when combined with the rising load excursion before the first small cycle and the falling excursion after the last small cycle. The crack extension during the intervening small cycles can be considerable, requiring rainflow to be carried out on the stress intensity, rather than load sequence. Such an exercise would have to be iterative in nature: to determine stress intensity sequence, crack growth has to be tracked, which strictly speaking, requires prior rainflow analysis.

\section{Applications of rainflow to crack growth analysis and testing}

As shown in the preceding sections, fatigue analysis can be performed exclusively on the rainflow cycle count table, without recourse to cycle-by-cycle estimates. The advantages of this option are obvious from the viewpoint of computation speed. Even more 

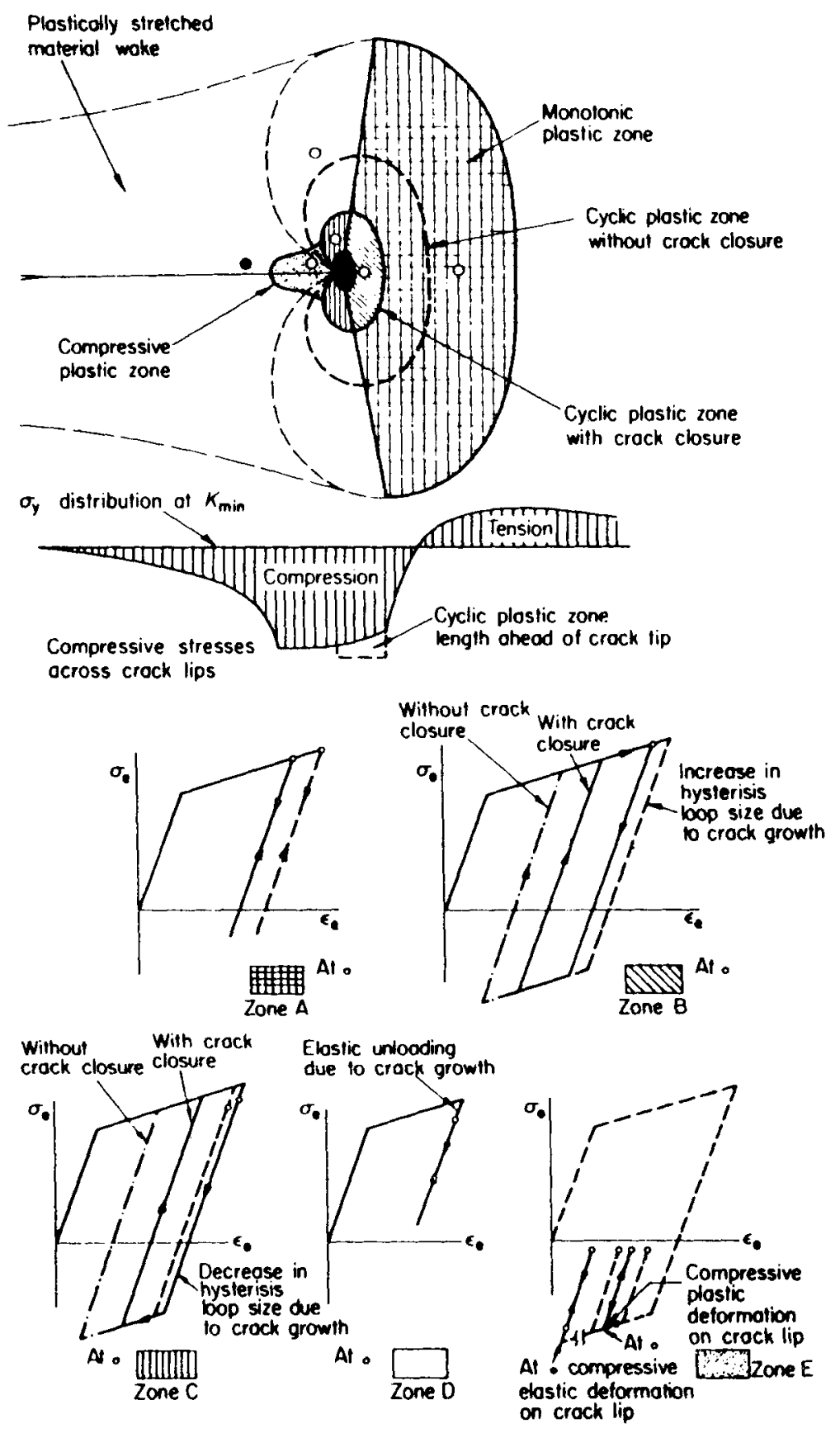

Figure 4. Schematic of crack tip cyclic stress-strain response (Raju 1980).

so in the case of crack growth analysis, whose computation time would otherwise be determined by crack growth rate. Proceeding on the premise that fatigue crack closure is the significant load interaction mechanism, it would follow that average crack growth rate for a sequence of ' $n$ ' arbitrary loads can be determined from its rainflow 

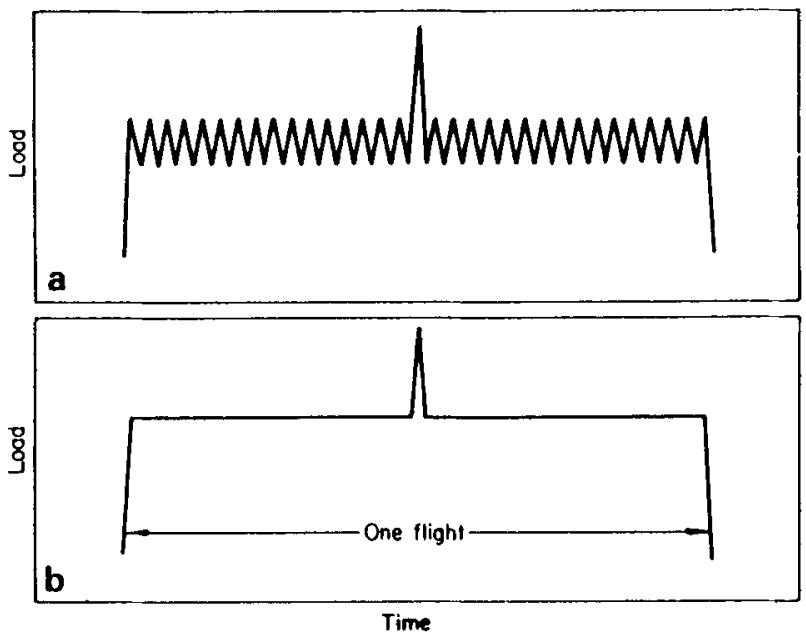

Figure 5. (a) Load excursions in a typical flight. (b) Major cycle.

cycle count from the following adaptation of the Elber equation for crack growth rate (Elber 1971):

$$
(\mathrm{d} a / \mathrm{d} N)_{\mathrm{av}}=(C / n) \sum_{i=1}^{n} \Delta K_{\mathrm{eff}, i}^{m}
$$

where, $\Delta K_{\text {eff }, i}$ is effective stress intensity range computed for the $i$ th rainflow counted cycle. In the summation, crack length is assumed to be constant.

\section{Cumulative damage in fatigue crack growth}

Equation (1) was used as the basis for an accelerated fatigue crack growth prediction method, that is described in (Sunder 1992). By operating on the table of Rainflow counted cycles, rather than on the source load sequence, cycle-by-cycle estimates are replaced by calculations on the rainflow table, which is considerably shorter. Crack growth analysis is thereby highly accelerated. Even so, the quality of predictions was found to be comparable or superior to the best available methods as indicated by the results in table 1 . The predictions listed in the table are for data used in a Round-Robin exercise involving a variety of aircraft wing load spectra. The results are for a $6 \mathrm{~mm}$ thick $\mathrm{Al}-\mathrm{Cu}$ alloy sheet material. As a rule, spectrum load fatigue crack growth predictions are better for larger material thickness. Spectrum load crack growth rate estimates are shown in figure 6 along with experimental data obtained at NAL on $7.5 \mathrm{~mm} 8090-\mathrm{T} 8771 \mathrm{Al}-\mathrm{Li}$ alloy plate stock and $1.6 \mathrm{~mm}$ thick $8090 \mathrm{C}-\mathrm{T} 81$ sheet material.

It is likely that for thinner sections down to $1 \mathrm{~mm}$, characteristic of airframe skin applications, prediction quality would have been worse. This may be attributed to the influence of other load interaction mechanisms, notably crack-front incompatibility (Schijve 1974; Zuidema \& Blaauw 1988), which are known to occur at smaller crack lengths in thinner material, thereby affecting growth in its early stages. Nevertheless, the sound analytical background of predictions based on rainflow, their compatibility with the LSS/LCF approach and the accelerated computations, thanks to the assumption of 


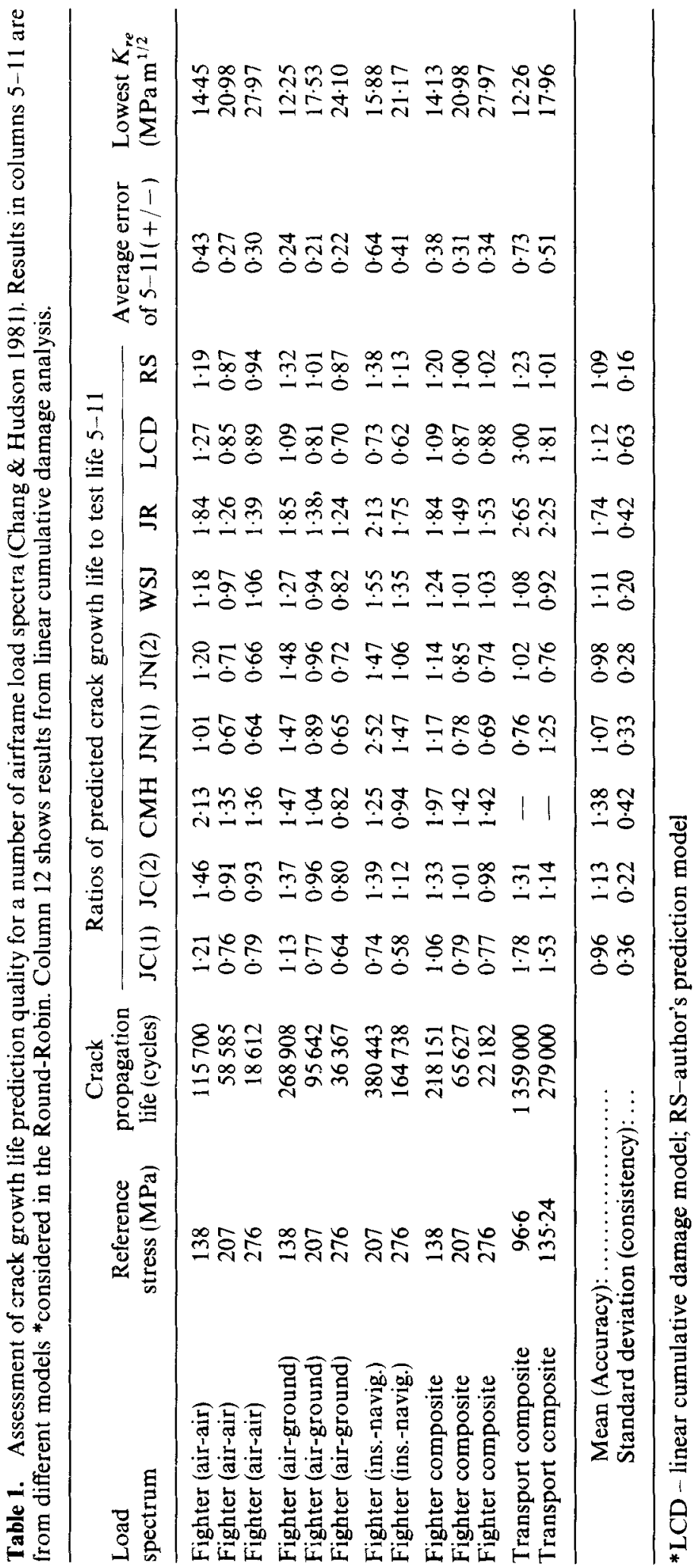



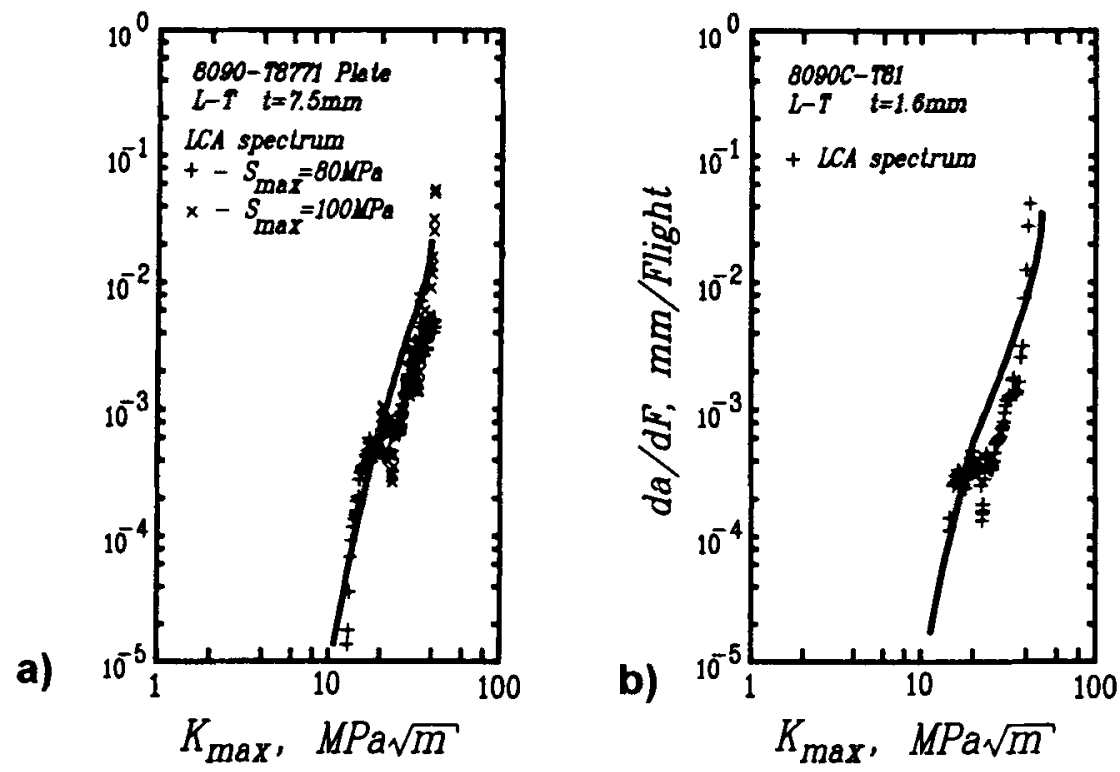

Figure 6. Experimental crack growth rates under Light Combat Aircraft (LCA) spectrum loading (curve) compared with experimental data (points). (a) $7.5 \mathrm{~mm}$ thick 8090 -T8771 Al-Li plate material, (b) $1.6 \mathrm{~mm}$ thick $8090 \mathrm{C}$-T81 sheet material.

a constant closure stress, renders them suitable for engineering application. The discovery of hysteresis in crack closure (whose description isforthcoming) and its implementation in the prediction model extended the scope of the analysis to short cracks at notches, thereby spanning a much larger fraction of total fatigue life.

When fatigue crack growth estimates are performed directly on the rainflow cycle count, it is possible to study the cumulative nature of fatigue damage, including the contribution of individual fatigue cycles to crack growth. Such an exercise was performed for a variety of load spectra (Sunder 1992). Figure 7 shows typical results from a cumulative damage analysis for crack growth under the FALSTAFF and TWIST load spectra. FALSTAFF is a fighter aircraft wing loading standard, dominated by manoeuvre loading, while TWIST applies to transport aircraft and is characterized by a large number of gust loads.

The nondimensionalised Range-Damage versus Exceedance (RDE) diagrams in figure 7 demonstrate qualitative differences between the two spectra. Each curve is identified by an encircled number. Curve 1 is the applied load range exceedance. It shows what percentage of the load cycles in the load spectrum exceeds a given applied stress range. Note that information on stress ratio of individual load cycles is lost in this curve. However, the concerned data are accounted for in damage analysis. Curve 2 shows exceedance of effective stress range, assuming linear cumulative damage (load interaction is ignored). It accounts for crack closure in individual load cycles as experienced under constant amplitude conditions. Curve 3 represents exceedance of effective stress range, after accounting for load interaction - it is assumed that closure in the largest cycle of the rainflow cycle will dominate. Curve 2 is usually above 3 , indicating that damage under spectrum loading is retarded due to load interaction. Note however, that in the case of the TWIST spectrum, there are locations, where 

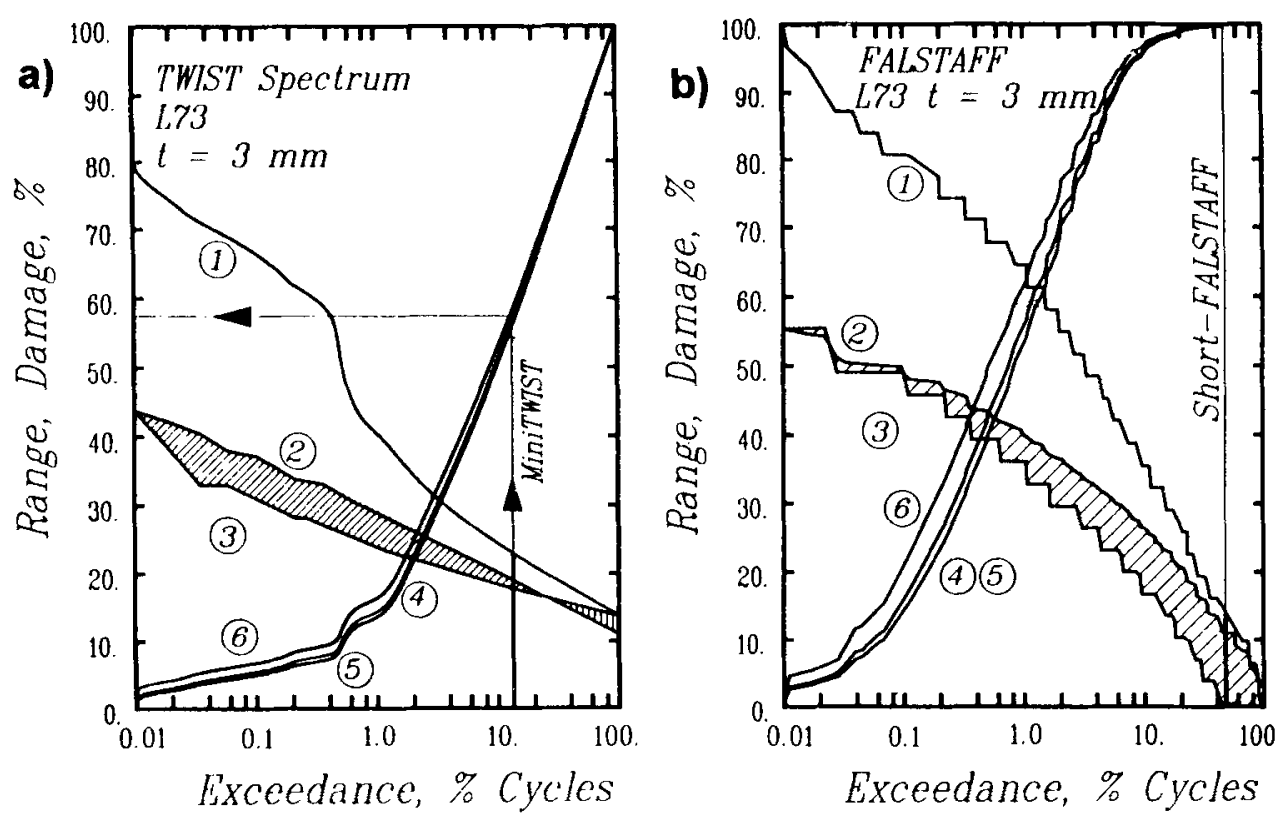

Figure 7. Range, damage-exceedance (RDE) diagrams for $\mathrm{L} 73 \mathrm{Al}-\mathrm{Cu}$ sheet material under TWIST (a) and FALSTAFF (b) load spectra. Shown in figures are cumulative damage content of MiniTWIST and ShortFALSTAFF load spectra, when compared to full sequences.

curve 3 goes over curve 2 , indicating the reverse. Finally, curve 3 represents damage exceedance.

In the case of the FALSTAFF spectrum, curve 4 shows that just $10 \%$ of the (largest) load cycles account for about $98 \%$ of all the damage. $90 \%$ of the (smaller) cycles could have been excluded from analysis without any impact on crack growth estimates. This explains why the Short-FALSTAFF spectrum widely used in tests gives the same results as the full spectrum (Schuetz 1989). The reverse holds true for the TWIST spectrum. We find that $10 \%$ of the cycles account for about $50 \%$ of total damage. While the FALSTAFF damage curve asymptotically approaches the $100 \%$ mark, the TWIST curve approaches peak value in a log-linear fashion. It would follow, that for the TWIST spectrum (and many other transport aircraft spectra as well), the large number of small cycles contribute significantly to damage. Figure 7 a explains why the MiniTWIST spectrum will provide retarded crack growth rates as observed in the literature (Schuetz 1989).

The RDE diagram provides a simple format to assess the fatigue damage potential of a load spectrum, without cumbersome cycle-by-cycle analysis and shows potential for application in endurance/durability studies as well as in testing.

\section{Realtime application of rainflow}

Experience shows that the fatigue process is load-history sensitive. In other words, should there be a need to evaluate endurance of a structural component, fatigue testing 
must be performed under a load sequence closely simulating the service environment. Computer controlled servohydraulic test systems permit such testing. The time of such testing however increases with test duration and an important question arises as to whether the load spectrum can be truncated to omit load cycles that may not anyway contribute much by way of fatigue damage. The RDE diagrams shown in figure 7 provide the analytical framework for omitting cycles from a load spectrum. This was the basis for the derivation of the Mini-LCA spectrum from the full LCA spectrum. As shown by the RDE diagram and crack growth rates in figure 8, while the Mini-LCA spectrum contains only $10 \%$ of the load cycles, it causes the same fatigue damage as the full LCA spectrum-crack growth rate data from the two fall into a single scatter band.

The Mini-LCA spectrum is an example of rainflow and RDE diagram based spectrum editing prior to a test. If cycle omission criteria can be specified prior to or even in the course of a test, an on-line rainflow analysis can be performed by the test application program on load sequence segments before their application on the test specimen (Sunder 1989). An example of a 'variable' criterion is omission stress intensity range, which will cause different number of cycles to be omitted depending on crack size. Figure 9 shows a schematic of how a source load sequence may be edited. Note that the sequence in figure $9 \mathrm{e}$ cannot be condensed any further because the rainflow algorithm will not see any more closed cycles. Thus, rainflow when implemented on a flight-by-flight basis will guarantee that at least the most severe cycle will be applied on the test coupon - irrespective of the specified omission criteria.

The application program 'pipelines' test code into the microprocessor-based test controller (Sunder 1985; Sunder \& Venkatesh 1990). Thus, while the test controller is

a)
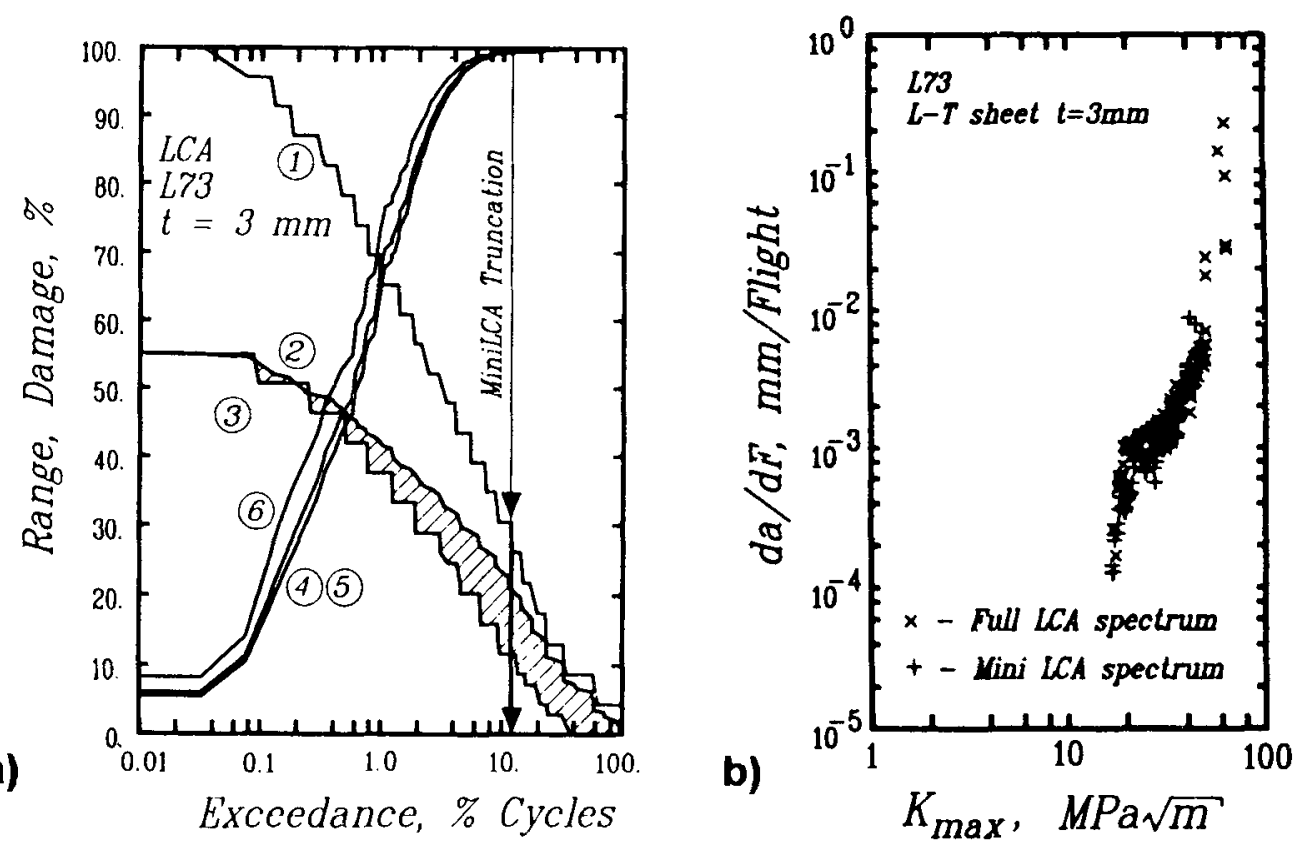

Figure 8. (a) RDE diagram for crack growth in LCA spectrum and L73 Al-Cu sheet material. Line shows the basis for derivation of MinilCA Spectrum. (b) Fatigue crack growth rates under full LCA and MiniLCA spectrum loading. 


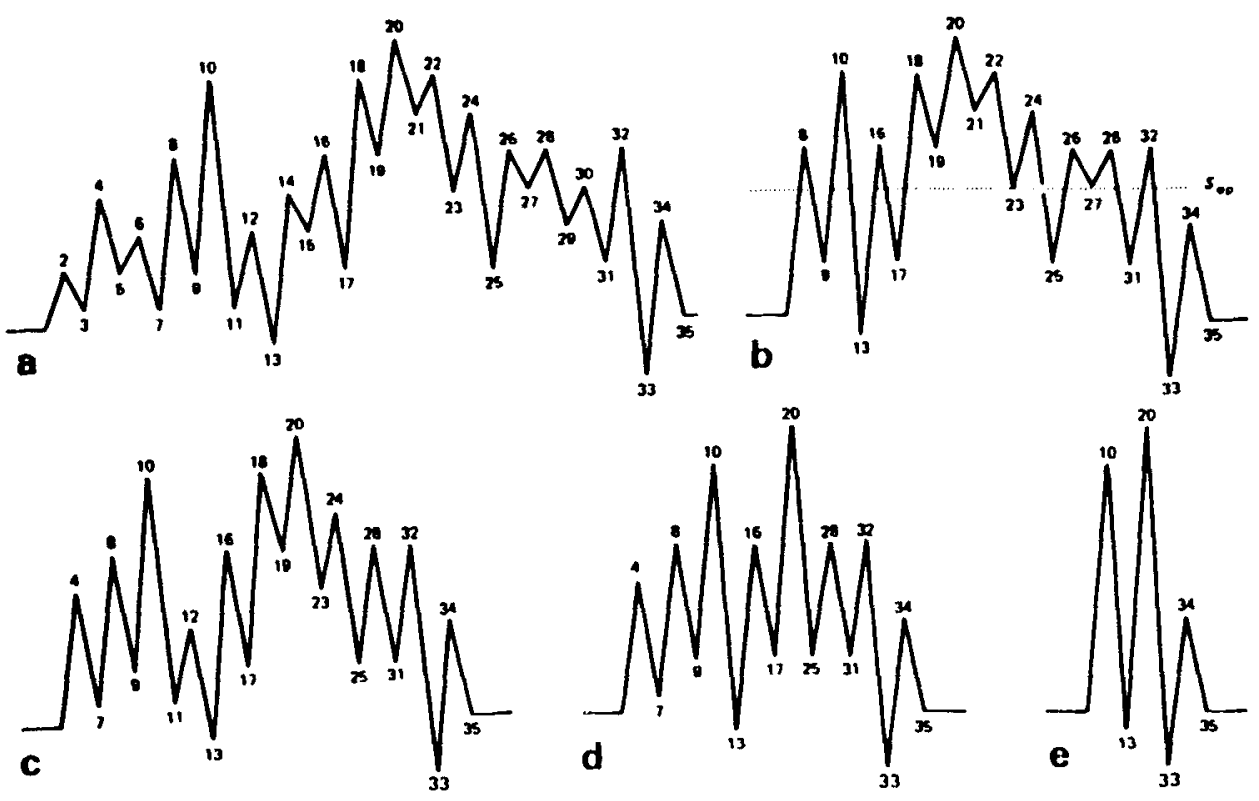

Figure 9. Consequences of on-line rainflow-based spectrum editing (Sunder 1989): (a) initial load sequence, (b) cycles below crack closure load omitted, and (c, d,e) cycles of progressively larger range omitted. Sequence cannot be condensed any further.

busy applying a segment of the load sequence, the host computer performs on-line rainflow to prepare the next segment. The speed with which the cycles are omitted is much faster than the speed with which the load frame can apply the remaining load cycles. To the observer, the test appears to proceed uninterrupted.

The scheme for on-line spectrum editing has been standard after 1984 in all spectrum load tests at NAL. It is used to accelerate pre-cracking (all minor cycles are deleted) and for accelerated data generation. It has also been used in iterative tests to determine effective crack closure level and threshold stress intensity valid for spectrum loading as shown in figure 10 (Sunder 1989). The principle behind closure stress determination is that a fatigue crack will not extend due to load cycles applied while it is fully closed. Their omission will therefore not retard crack growth. Starting from a high level, by selecting progressively decreasing omission levels in successive tests, a particular level will be identified associated with no further acceleration in crack growth rate. This is the effective closure level for the given load spectrum. Effective threshold stress intensity range is determined in a similar fashion. Progressively smaller omission ranges are specified for stress intensity. While the range is above a certain threshold, crack growth rate will accelerate. Below this point, crack growth rates will not see any change. This value is treated as the effective threshold stress intensity for the spectrum.

As shown in figure 10 (top), the crack closure value determined from iterative testing is $2.5 \mathrm{~g}$ or about $28 \%$ of maximum stress, which compares well with estimates using other techniques for the same material. On the other hand. it was surprising to find that threshold stress intensity range was effectively near zero. This is a significant observation and may explain why even very small load cycles are damaging in transport spectra, by their 

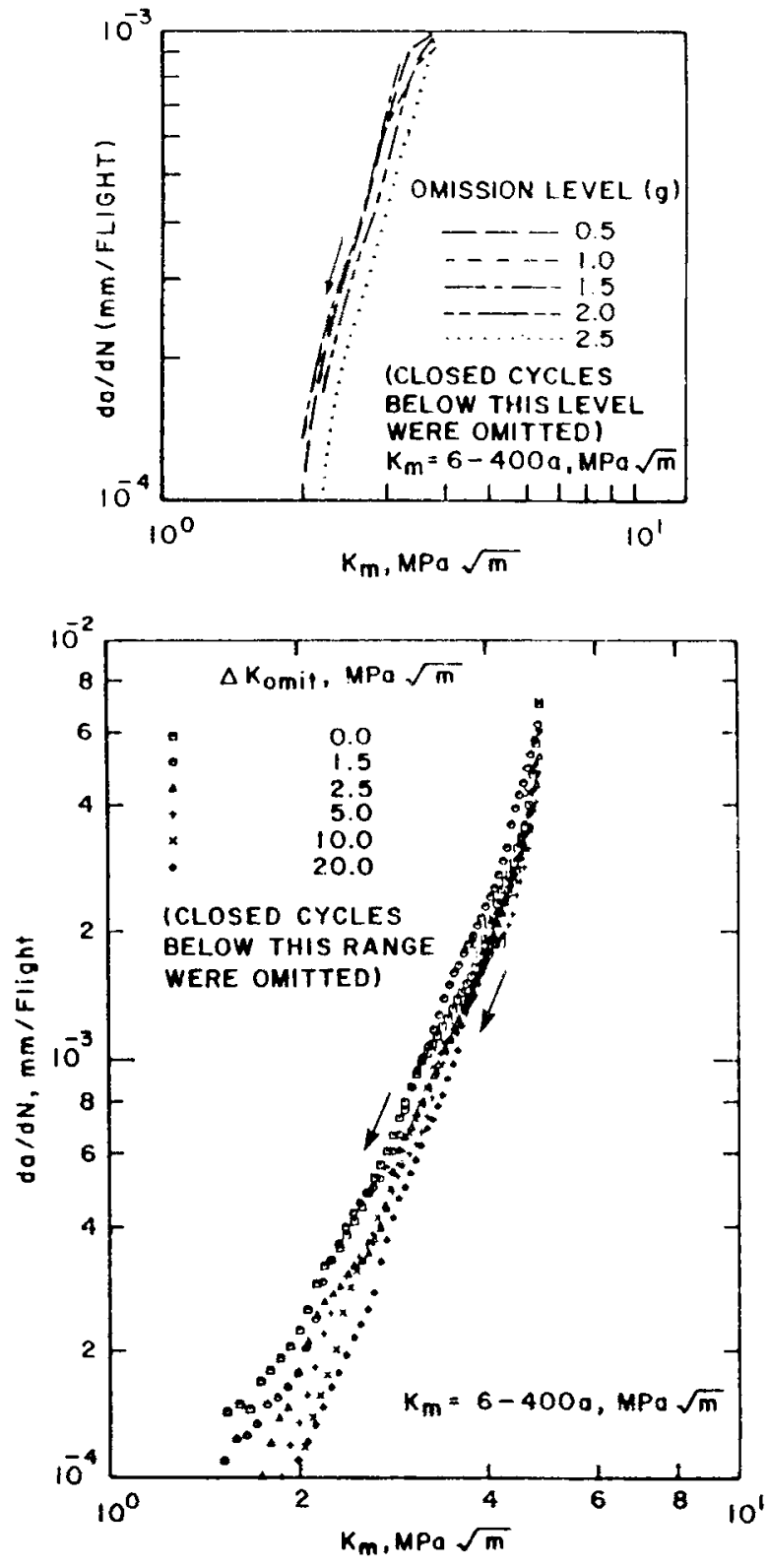

Figure 10. Results from tests on aluminium-alloy sheet specimens with on-line spectrum editing (Sunder 1987): (top) tests with different omission level, and (bottom) tests with different omission $\Delta K$. All tests used the same linearly decreasing $1-g$ related $K$-function listed in the figures. Spectrum clipped at $6 g$.

sheer number. It would follow that threshold studies under constant amplitude loading may yield unconservative results when used in estimates of spectrum load crack growth.

\section{Fatigue crack closure}

Linear elastic fracture mechanics (LEFM) suggests that the slope of applied load versus crack opening displacement (COD) depends only on Young's Modulus and crack 
length. This implies a linear load versus COD relationship. In experiments on 2024-T3 Al-alloy sheet centre cracked specimens, Elber (1971) discovered that the slope in the load versus COD relationship remains linear only over a certain upper fraction of load level. Below this load level, the slope increases, implying a diminishing crack length. This effect was attributed to fatigue crack closure, whereby, the stretched wake formed by the advancing crack tip closes even under tensile loading, with the near tip fracture surfaces transferring load in bearing. The area of closure increases with unloading, as indicated by the increasing slope in the load versus COD curve. A closed crack obviously does not see damage due to fatigue cycling. Elber (1971) thereby proposed the effective stress range concept, whereby it is assumed that crack growth occurs only a due to the portion of the applied load cycle when the crack is open. While Elber's (1971) observations were on closure due to piasticity, more forms of closure were reported by subsequent research, such as oxide induced closure, roughness effects, etc. (Suresh et al 1981: Ritchie \& Suresh 1982; Suresh \& Ritchie 1982). It may be fair to say that fatigue crack closure has seen more publications than research on any other phenomenon in FCP, indicating the attention it has attracted from researchers the world over.

For a given material and thickness, crack closure stress ratio, $S_{\mathrm{cl}} / S_{\max }$, increases with stress ratio. Elber's discovery thereby explained for the first time, how mean stress affects sub-critical fatigue crack growth rate. Up to this point, mean stress effects were correlated by a suitable approximating equation. In principle, it could be argued that existing approximations were adequate considering that crack closure stress required experimental determination anyway. The same does not hold true however for random load conditions, typical of service environment. It was observed that crack opening stress, $S_{\text {up }}$, remains more or less contant under random loading (Elber 1976; Schijve 1979). effectively eliminating the effect of a large component of fatigue loading. $S_{\text {op }}$ would be controlled by the crack tip deformations due to the larger loads. explaining the effect of overloads on FCP under variable amplitude loading. The ability of fatigue crack closure to explain load interaction effects and the increasing power of analytical tools to model crack closure under variable amplitude loading have made the phenomenon a popular choice in life prediction models (de Koning 1981; Newman 1981; Dougherty et al 1992; Vormwald et al 1992).

The significance of fatigue crack closure in practical applications makes $S_{\text {op }}$ an important variable in experimental and analytical studies. Yet, even after about 25 years of research and hundreds of publications on the subject, the engineering community does not have a standard procedure for its experimental determination unlike other mechanical properties such as yield stress. $K_{1 c}, J_{1 c}$ etc. It may be noted that even a universally accepted definition of $S_{\mathrm{cl}}$ is lacking. The measured value of $S_{\mathrm{cl}}$ using Elber's COD gauge depends on the location of the gauge with respect to the crack tip. More precise laser interferometry based measurements using indents near the crack tip have also shown the same effect. Many other techniques have been proposed for measuring crack closure. These include ultrasound, DC-potential drop (DCPD), acoustic emission etc. Being diagnostic in nature, these techniques cannot avoid the subjective element of data interpretation. This introduces inaccuracies and discrepancies in estimates, which are rather unacceptable, considering the power relationship between crack growth rate, $\mathrm{d} a / \mathrm{d} N$ and effective range, $\Delta K_{\text {eff }}$.

Proceeding on the assumption that $\mathrm{d} a / \mathrm{d} N$ is in fact controlled exclusively by $\Delta K_{\text {eff }}$, it would follow that the crack closure phenomenon must also manifest itself in striation 


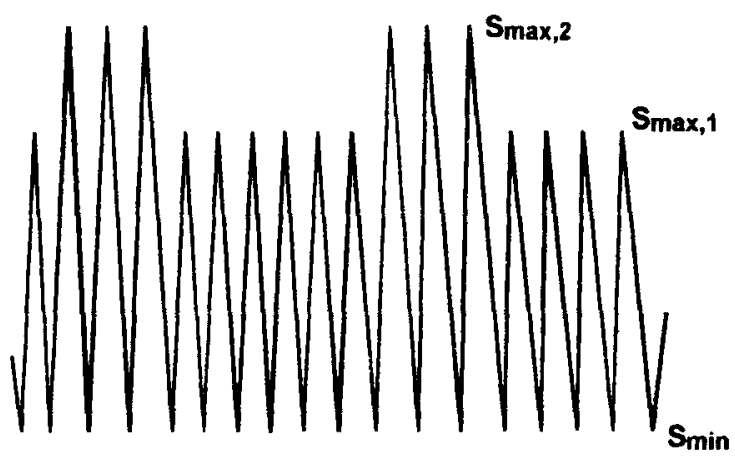

a)
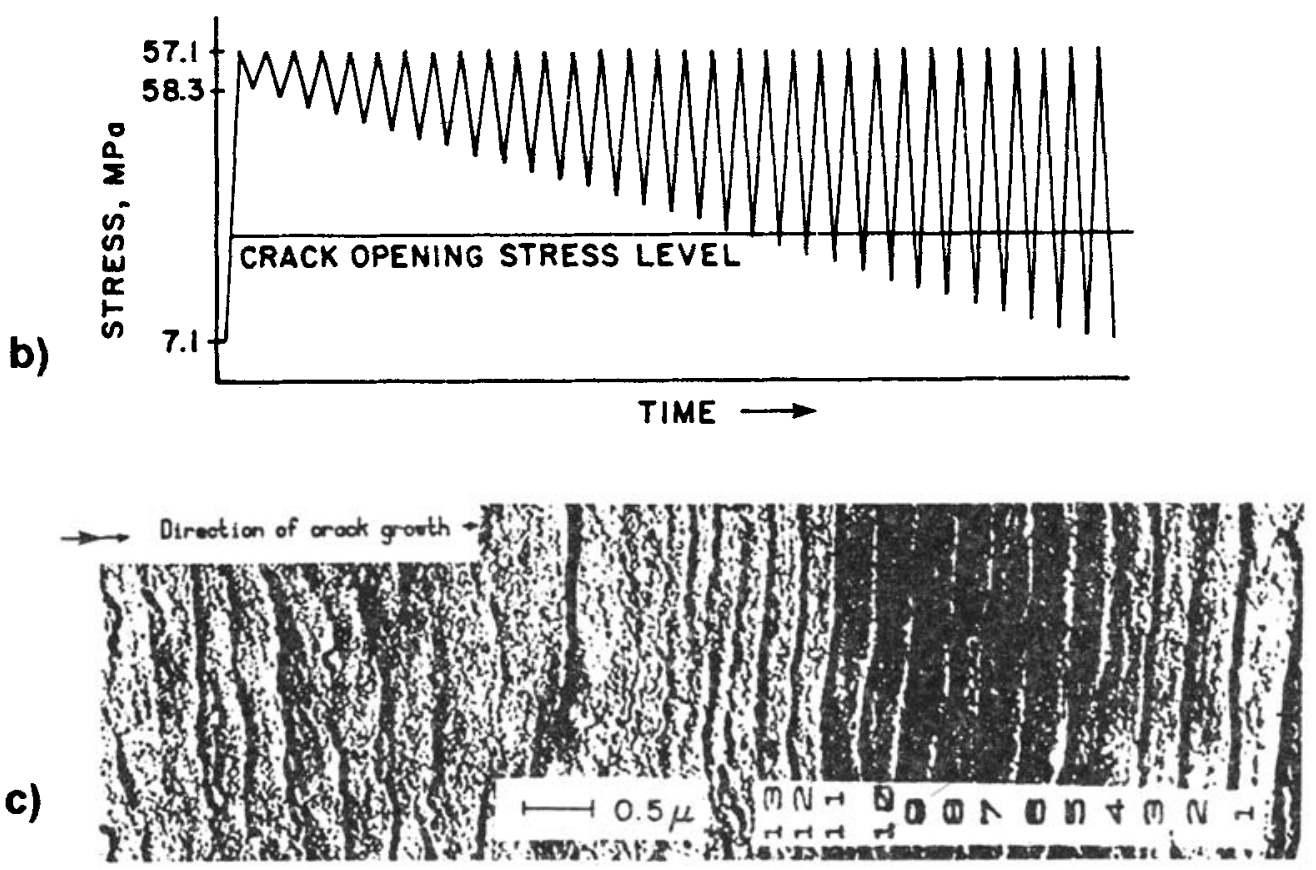

Figure 11. Load sequences used for fractographic assessment of crack closure. (a) Constant $S_{\min }$ and varying $S_{\max }$ (Pelloux et al 1980), (b) constant maximum stress and varying minimum stress (Sunder \& Dash 1982), (c) striation pattern obtained from load sequence in (b).

patterns on the fracture surface. In many materials, individual load cycles form a striation on the fracture surface. The striation spacing indicates crack extension per cycle. Consider the simple load sequence in figure 11a in the framework of the Elber equation for crack growth rate:

$$
\frac{\mathrm{d} a}{\mathrm{~d} N}=C \Delta K_{e f f}^{m}
$$


Cycles 1 and 2 have the same $S_{\min }$, but $S_{\max , 2}$ exceeds $S_{\max , 1}$. In the event of absence of crack closure, the striation spacing ratio, $s_{r}$, for the two cycles will be given by:

$$
s_{r}=\left[\frac{S_{\max , 1}-S_{\min , 1}}{S_{\max , 2}-S_{\min .2}}\right]^{m}
$$

In the presence of crack closure (3) is rewritten as:

$$
S_{r}=\left[\frac{S_{\max , 1}-S_{\mathrm{cl}}}{S_{\max , 2}-S_{\mathrm{cl}}}\right]^{m}
$$

Given $s_{\mathrm{r}}$ from electron fractography, $S_{\mathrm{cl}}$ can be determined from (4). This idea formed the basis for an experimental study by Pelloux et al (1980). The technique proposed by them relies on the validity of the exponent, $m$. This material constant is determined from experimental macro crack growth rate data, which need not coincide with striation spacings if other crack-extension mechanisms are involved, along with striation formation. In fact, Pelloux et al obtained $S_{\mathrm{cl}}$ estimates assuming different values for the exponent.

The shortcoming in the above technique was overcome by Sunder $\&$ Dash (1982), who proposed a different type of load sequence that is schematically described in figure $11 \mathrm{~b}$. A programmed load sequence with constant $S_{\max }$ and $S_{\min }$ varying gradually from cycle to cycle is used in the test. Assuming $S_{\mathrm{cl}}$ is constant over this block of cycles, at the cycles with $S_{\min }$ less than $S_{\mathrm{cl}}$ will leave behind equally spaced striations. By simply counting the number of equally spaced striations in a load block, one can directly determine $S_{\mathrm{cl}}$ (see typical striation pattern in figure 11c). The technique is based on the hypothesis that only fatigue crack closure can explain equally spaced striations from the type of load sequence shown in figure $11 \mathrm{~b}$. It is not sensitive to the exponent, $m$, or in fact, even the nature of the growth rate equation. Besides, the method offers the possibility of determining $S_{\mathrm{cl}}$ with a known degree of error equal to the difference in $S_{\min }$ between successive cycles. On the other hand, it must be noted that in actual practice, there is an element of subjectivity in counting off equally spaced striations. Another disadvantage with the technique is that it requires a specially designed load sequence and cannot be easily adapted to a particular sequence of interest to the user. The material must be conducive to striation formation and finally, the technique provides best results with TEM, which is a rather cumbersome exercise.

The above method for crack closure assessment has been used in a number of studies on the crack closure phenomenon. It confirmed for example, that crack closure close to the surface of the specimen is greater than in the mid-thickness region, where plane strain conditions prevail (see figure 12) (Sunder \& Dash 1982).

\section{Crack closure development in notch root corner cracks}

One of the major advantages of the fractographic technique for closure measurement is that estimates are local in nature. This feature was exploited in a study which involved application of a 'closure block' along with a binary coded load block that 'punches' the cycle count onto the fracture surface (Anandan \& Sunder 1987). The technique of binary coding was demonstrated in eariier work, where in alphanumeric information 

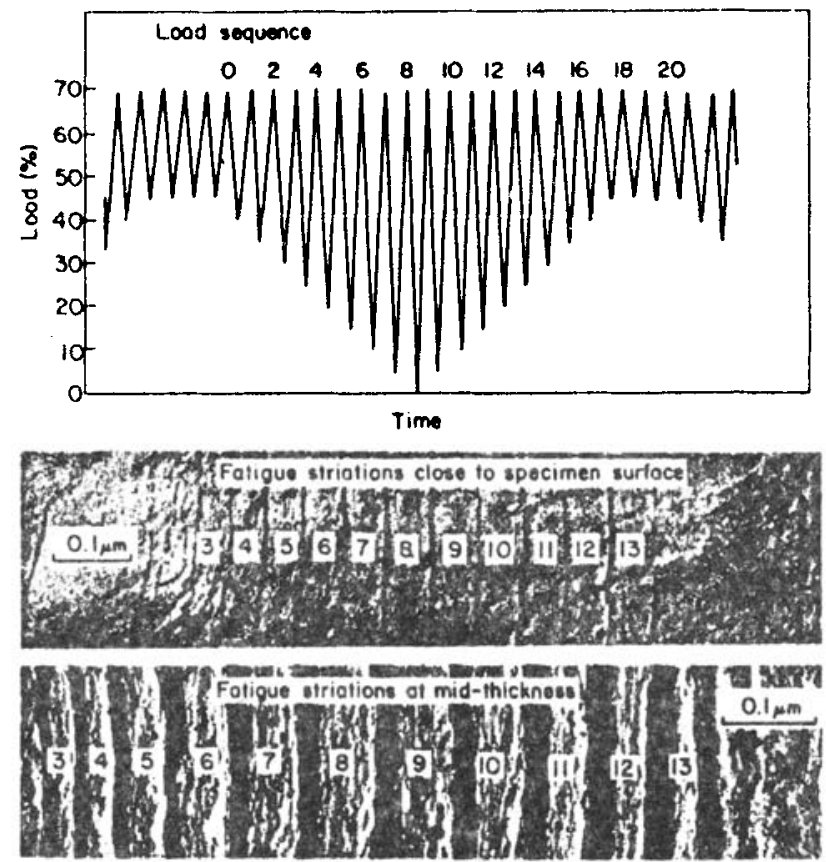

Figure 12. More equally spaced striations are found near the surface than at the mid-thickness area, indicating less closure at mid-thickness (Sunder \& Dash 1982).

was fractographically encoded into a striation pattern (see figure 13) (Sunder 1983). This opened up the possibility of introducing event markers on the fracture surface, which can be identified during subsequent fractography, thus permitting crack front and crack closure mapping for part-through cracks.

A fractographic study on closure development was performed on a keyhole type of SENT specimen, with a corner crack emanating out of a $0.25 \mathrm{~mm}$ deep crack initiator (Anandan \& Sunder 1987). The tests were conducted after application of various levels of prior static overload to examine how notch root residual stresses will affect the evolution of crack front and associated $S_{\mathrm{cl}}$ values. Some results appear in figure 14 . Note the higher levels of $S_{\mathrm{cl}}$ close to the notch surface. $S_{\mathrm{cl}}$ varied by almost $50 \%$ depending on location. The binary coded striation patterns were used to decode the cycle count and thereby build up the crack front shape and map the growth of the corner crack at the notch root. It was found that residual compressive stresses caused by prior static tensile overload reduce the 'local mean stress' along the notch surface (see figure 15). This retards local crack front progress because of reduced effective stress as indicated by increased closure stress levels.

The Jo Dean Morrow and Smith--Watson-Topper equations for LCF based fatigue damage (Morrow 1968; Topper et al 1970) account for residual stress effects by introducing a local mean stress correction factor. While this correction is empirical in nature, the notch root stress strain response to applied elastic loading is simulated by the Local Stress-Strain (LSS) method, that is based on Neuber conversion (Neuber 1961) and Masing model (Wetzel, 1971). As demonstrated by the data in figure 15, the same Neuber con ersion can be used to determine notch root stress ratio and associated $S_{\mathrm{cl}}$ values to provide a fracture mechanics based explanation for reduced 


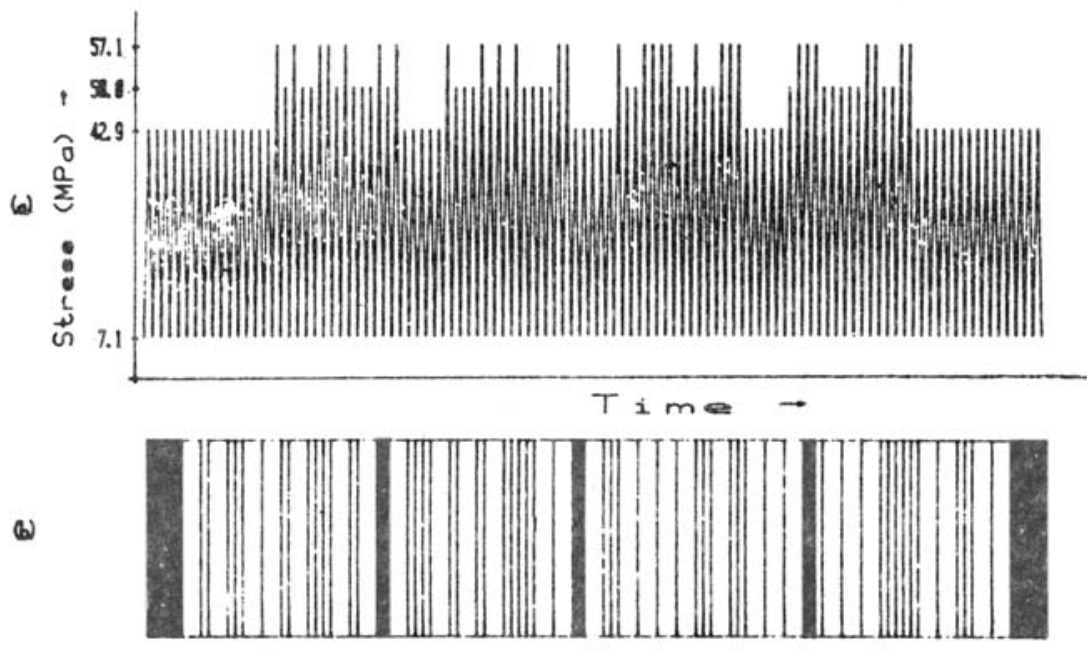

Direction of crock growth

Lood sequence and expected striotion pottern

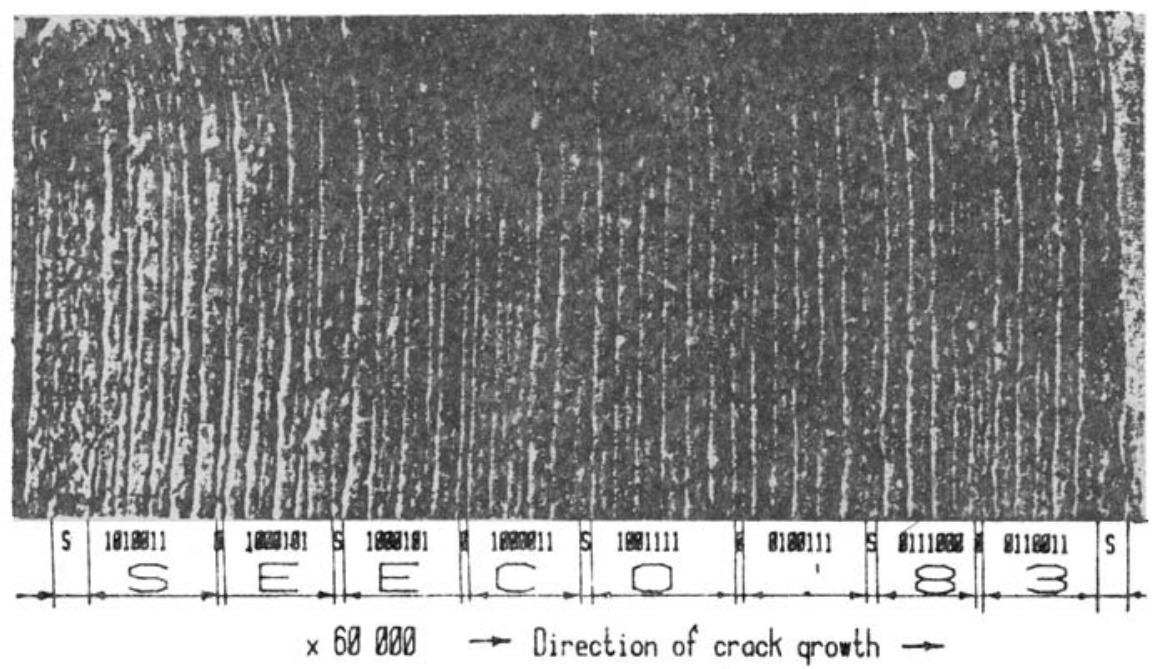

Figure 13. Binary coded load sequence (a) and striation pattern (b) representing the character string "SEECO'83" (Sunder 1983). The same technique was used to punch the load cycle count on to the fracture surface for event registration purposes.

fatigue damage in the presence of compressive residual stresses: local stress ratio is lower than applied stress ratio, the fatigue crack remains closed over a larger portion of the load cycle and crack growth is retarded by the reduced effective stress intensity range. These results are for fairly large cracks, at least a fraction of a millimeter in size. Subsequent research whose description is forthcoming showed that the same conclusion holds true for much smaller cracks that can form at the very commencement of fatigue cycling. 

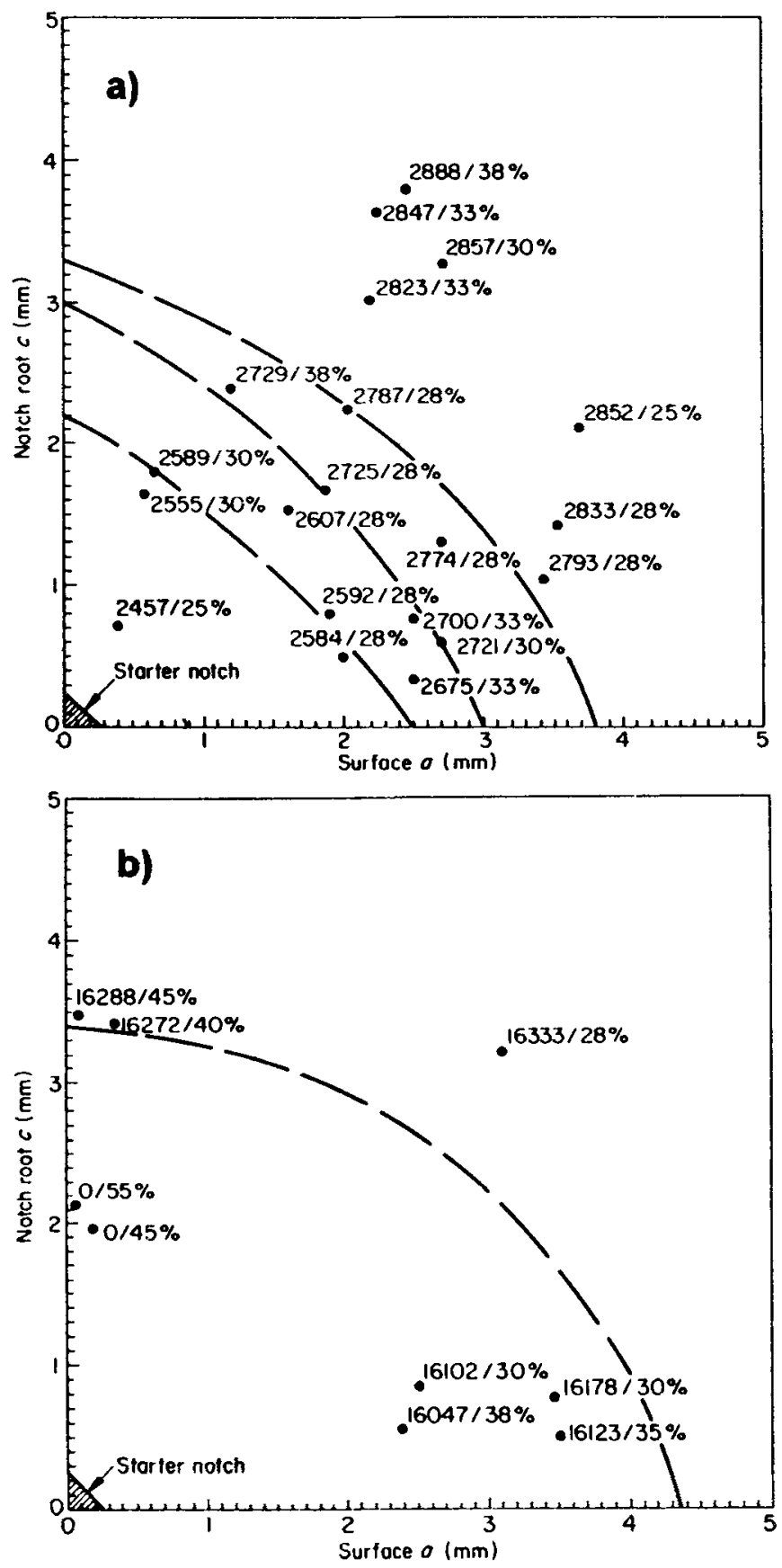

Figure 14. Fractographically determined crack opening stress levels for a key hole notch specimen without prior overload (a) and after $100 \%$ prior tensile overload (b) (Anandan \& Sunder 1987). 


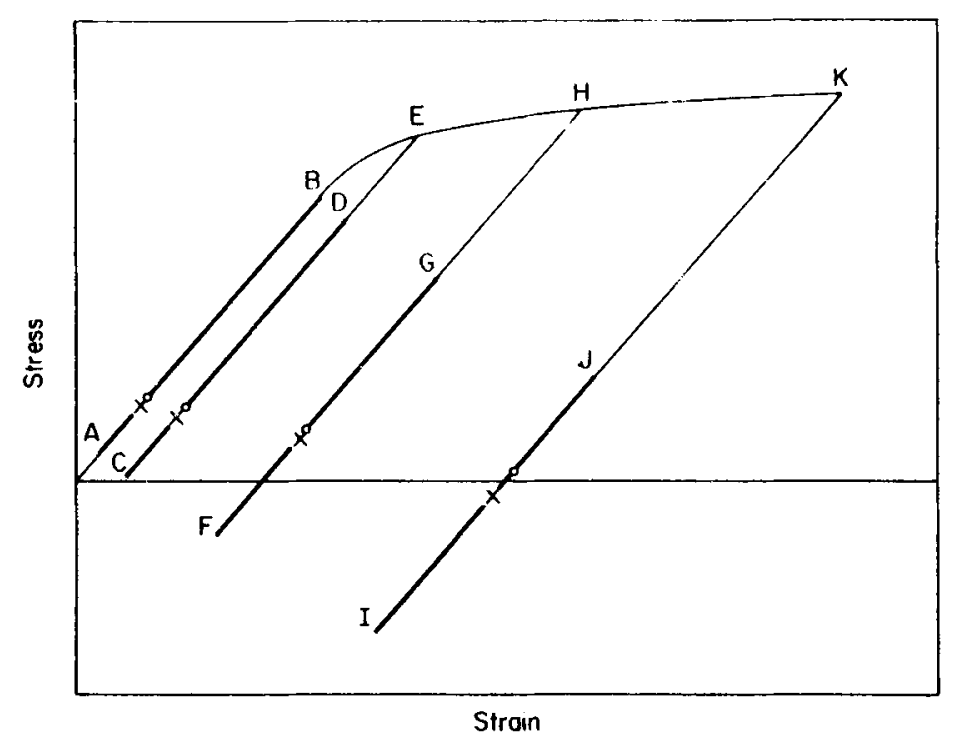

Figure 15. Tensile overload of different magnitude $(E, H, K)$ leaves behind progressively greater compressive residual stress that reduce local stress ratio, As a consequence, the crack is closed over a larger fraction of the load cycle, leading to retarded growth. Crosses are fractographically estimated notch root $S_{\mathrm{op}}$, circles are from literature data for given stress ratio (Anandan \& Sunder 1987).

\section{Hysteresis in fatigue crack closure}

Consider the arbitrary load sequence and associated notch root stress-strain response shown in figure 16. Cycles A, B and cycles C, D are of the same applied magnitude. Yet, because of the notch root stress strain hysteresis, larger loads applied between these similar cycles induce residual stress that change their local mean stress and strain. As a consequence of this load interaction, cycles $B$ and $D$ have a lower mean stress than cycles $A$ and $C$ respectively. When interpreted from a fracture mechanics viewpoint, crack extension in cycles $B, D$ should be less than in $A, C$ respectively.

Experiments were conducted to investigate crack closure behaviour under conditions of varying local mean stress (Sunder 1991). Testing was on L165 Al-Cu alloy coupons with a central hole, with natural crack initiation under the test sequence shown in figure 17. This sequence contains a number of smaller cycles superposed on a major cycle. The simulated notch root stress-strain response to this sequence is also shown in the figure. The cycles on the rising and falling half of the major cycle are equal in magnitude and applied stress ratio. An attempt was made to determine crack closure stress, $S_{\mathrm{cl}}$ for each of these cycles. This was done by introducing into each of them, a suitable crack closure block that was described earlier, to give the rather complex load sequence which appears in a typical fractograph shown in figure 18. These experiments revealed that under variable amplitude inelastic notch root stress-strain, the crack will not open at a constant applied stress level in individual cycles. This phenomenon can be explained on the premise that crack closure stress, $S_{\mathrm{cl}}$ is distinct from and always greater than crack opening stress, $S_{\mathrm{op}} \cdot S_{\mathrm{cl}}$ and $S_{\mathrm{op}}$ for the major cycle in 


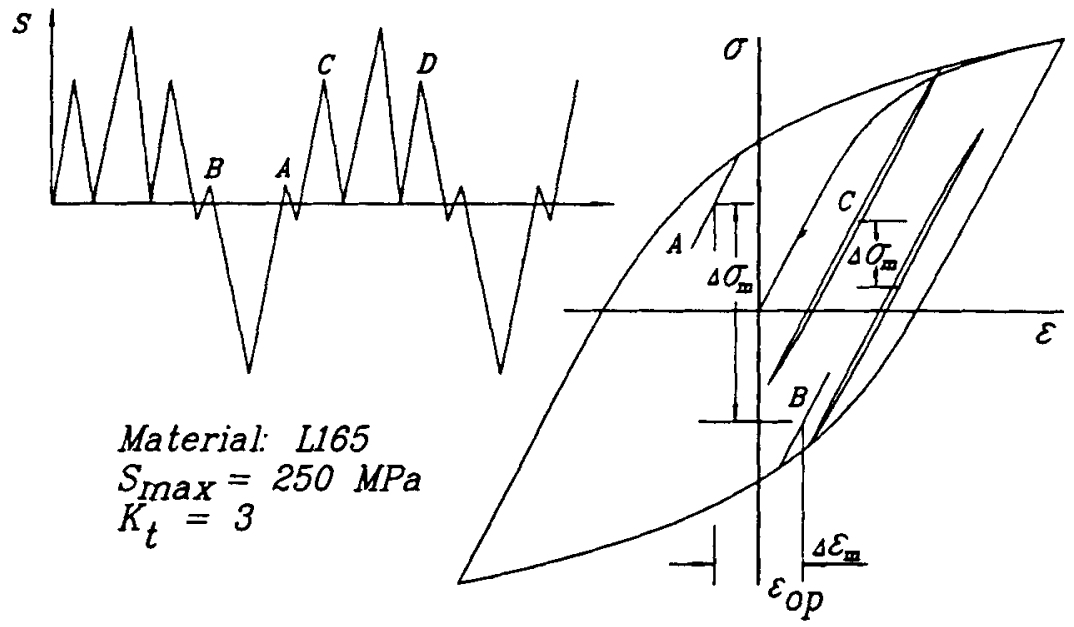

Figure 16. Notch root stress strain response to a complex load sequence.

a sequence will form an interval over which $S_{\mathrm{op}, \mathrm{i}}$ in individual embedded cycles will fall. Fatigue crack extension is controlled by the rising segment of the load excursion between $S_{\mathrm{op}}$ and $S_{\max } . S_{\mathrm{el}}$ while being of academic interest under constant amplitude loading, acts as an upper bound for $S_{\text {op }}$ in smaller embedded cycles.

Hysteretic crack closure behaviour is schematically explained in figure 19. In the case of a long crack under elastic loading, $S_{\mathrm{op}}$ and $S_{\mathrm{cl}}$ are similar (figure 19a). $S_{\mathrm{op}, i}$ in individual cycles under complex loading will not therefore see substantial variation. In

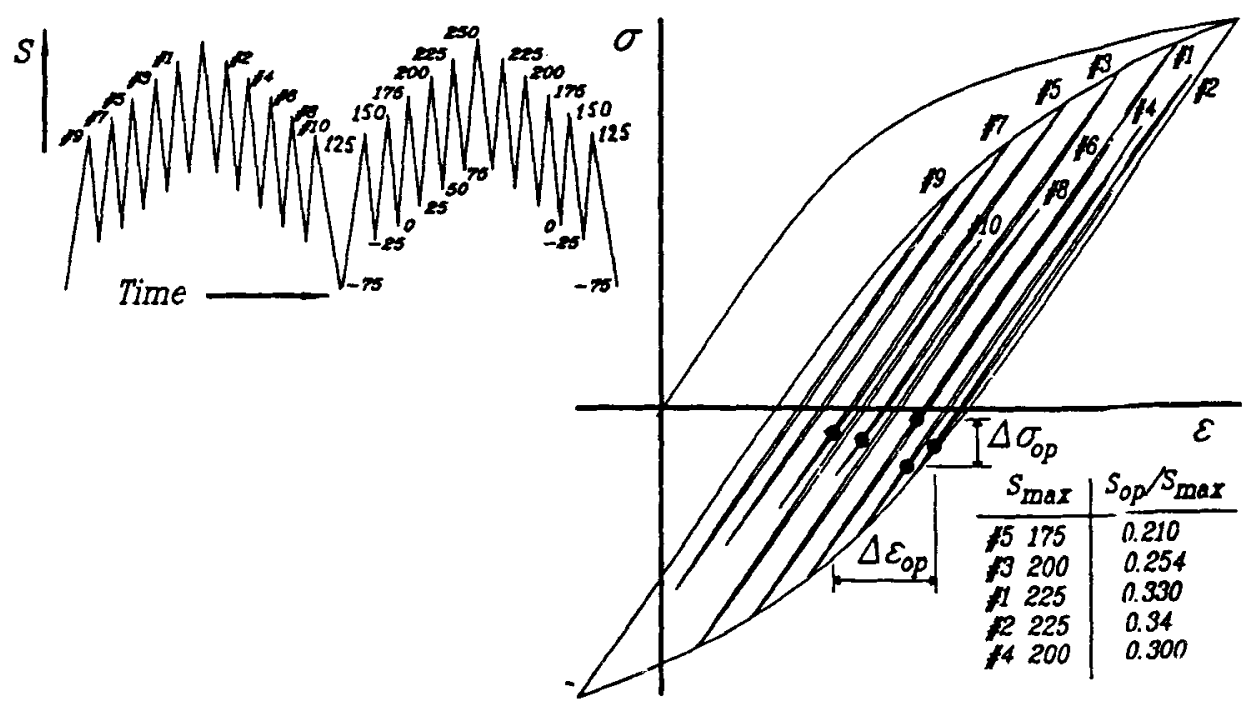

Figure 17. Load sequence with many embedded cycles on rising and falling half. This sequence was modified suitably for fractographic estimates of $S_{\mathrm{op}}$ in the embedded cycles (also see figure 18). 


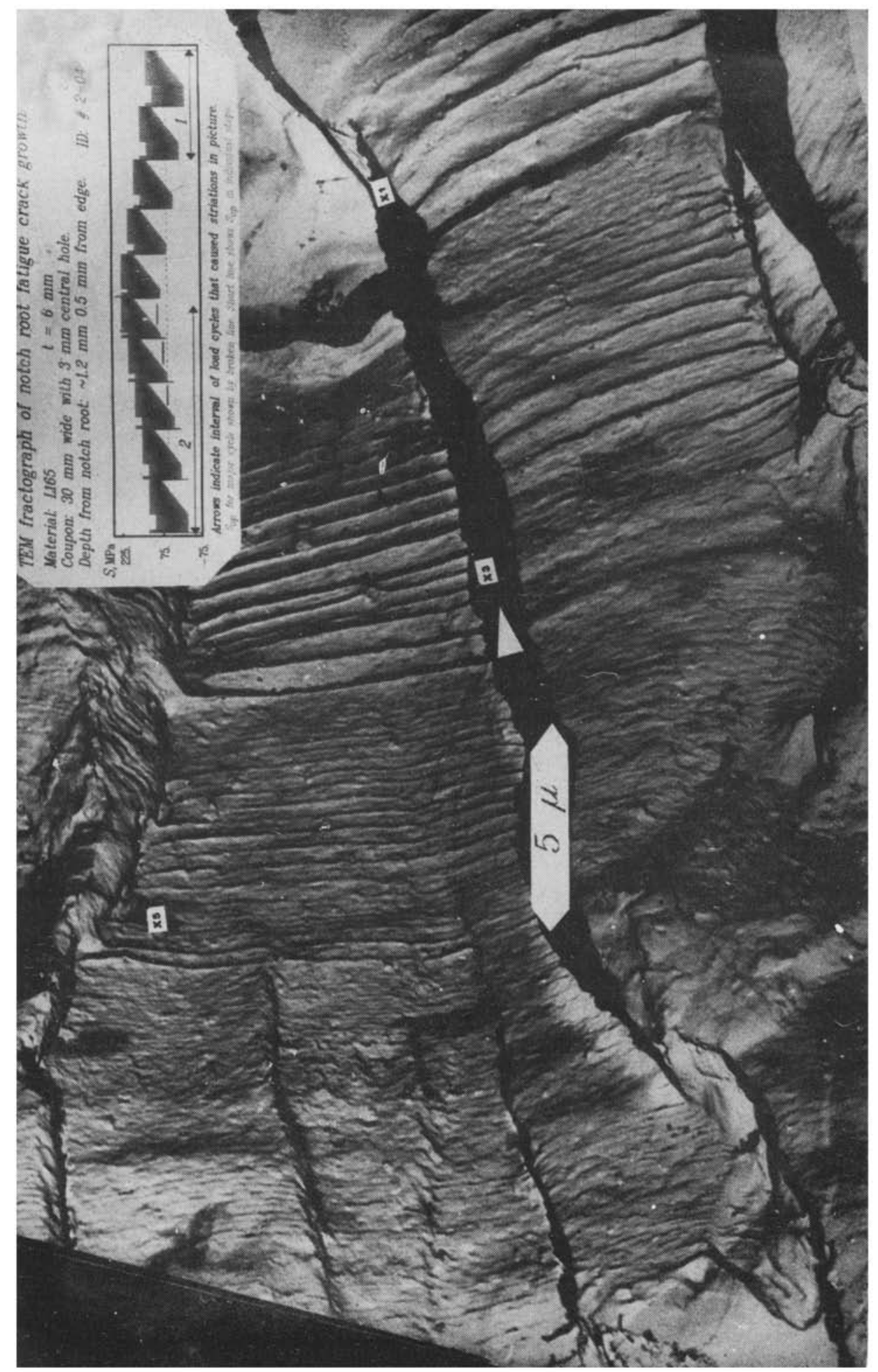

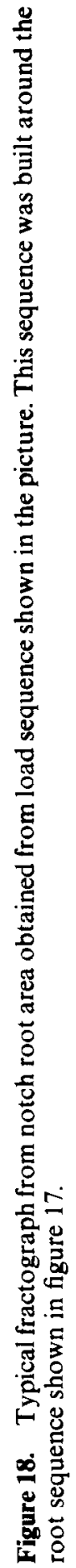




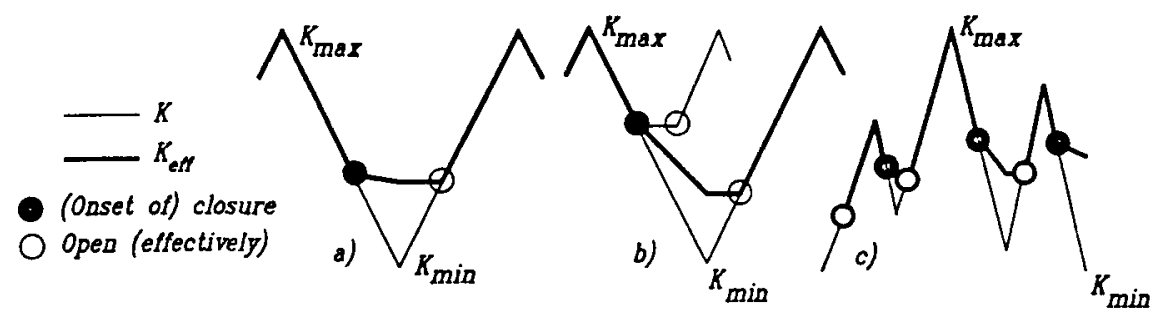

Figure 19. Schematic of hysteretic crack opening and closure under constant amplitude elastic (a) and inelastic (b) loading, and under arbitrary loading (c).

contrast, consider the case in figure $19 \mathrm{~b}$, showing closure response for a notch root crack under conditions of local cyclic inelasticity. The onset of closure $\left(S_{\mathrm{cl}}\right)$ occurs at a stress level much higher than $S_{\mathrm{op}}$. This is due to the stress excursion from $S_{\mathrm{cl}}$ down to $S_{\min }$, which lowers the stress at which the crack will open. The significance of this difference can be understood if we consider the possibility of applied stress not falling below $S_{\mathrm{cl}}$, but rather, going up once again towards $S_{\max }$. In this event, the crack would open immediately (see figure 19b). Figure 19c shows the interplay between closure and opening stess under a complex load sequence, that can be described by a linear hysteretic' model (Sunder 1991).

The hysteretic nature of $S_{\mathrm{op}}$ variation is qualitatively similar (in terms of its influence on damage due to crack extension) to that expected from load history effects on notch root local mean stress variation (in terms of damage estimates from LCF/LSS considerations). This provides a fracture mechanics foundation to explain well-known history sensitive local mean stress effects that were so far modelled empirically. Itmay also be noted that in the absence of hysteresis in crack closure, one would not be able to explain (from a fracture mechanics viewpoint), why notch root fatigue damage is load history sensitive.

\section{Fractographic characterization of crack closure hysteresis}

The work described in the preceding sections highlights the qualitative similarity between the hysteretic nature of notch root mean stress and notch root crack closure stress variation under complex loading. In an effort to develop a procedure for crack growth calculations under spectrum loading, a study was conducted to estimate $S_{\text {op }}$ and $S_{\mathrm{cl}}$ values for Al-Cu alloy 2014-T6511 (L168 or HE15AST) under a variety of test conditions (Sunder et al 1993a).

Figure 20 provides a summary of experimental results at $R=-0 \cdot 3$. This s representative of stress ratio of the major cycle in most aircraft wing lower surface load spectra. Clearly, $S_{\mathrm{op}}$ and $S_{\mathrm{cl}}$ are barely different for long cracks under elastic loading. But as crack size diminishes and stress level increases, the difference between the two increaes substantially. While $S_{\mathrm{cl}}$ varies only marginally, $S_{\mathrm{op}}$ appears to fall rapidly below zero stress when the notch root sees cyclic inelastic loading. It follows that a fatigue crack can in principle be open in compression and implies that an assumption that negative stress intensity can be ignored may be unconservative. Indeed, experiments at $R=-3 \cdot 3$ confirmed that a notch root crack can be open over a large portion of 


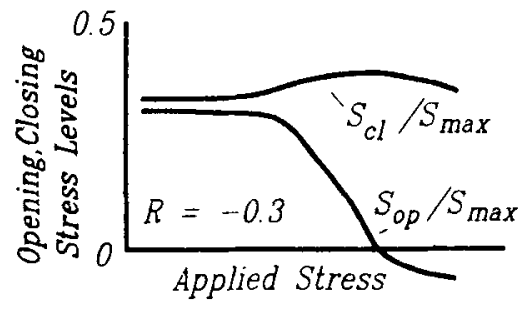

Figure 20. Schematic summary of measured closure and opening loads versus stress range at $R=-0.3$ in $6 \mathrm{~mm}$ thick L168 extruded bar stock (Sunder et al 1993a).

a compressive load cycle (Sunder et al 1993a). All these experiments used the specially designed load sequence and estimates of $S_{\mathrm{op}}$ and $S_{\mathrm{cl}}$ based on the number of equally based striations.

The $S_{\mathrm{op}}$ and $S_{\mathrm{cl}}$ values obtained in the above study along with laboratory data on crack growth rate in laboratory coupons under constant amplitude loading and the proposed hysteretic model for crack closure variation formed the basis for the framework for notch root short crack growth calculations (see figure 21). The influence of notch root cyclic inelasticity on crack driving force was accounted for by introducing a correction factor on stress intensity. In this manner, the cyclic stress-strain response of the material forms an essential input for crack growth computations. Calculations were made for notch root crack growth under various conditions of the FALSTAFF load spectrum, starting from an initial crack size of under 30 microns. These results are summarized in figure 22 and appear to support the application of fracture mechanics in fatigue crack growth analysis starting from extremely small and barely detectable crack sizes through to failure.

Figure 23 provides a schematic of how load interaction effects can be interpreted in the light of experimental observations and modelling described in the previous sections. Figure 23a shows a programmed load sequence with periodic overloads and

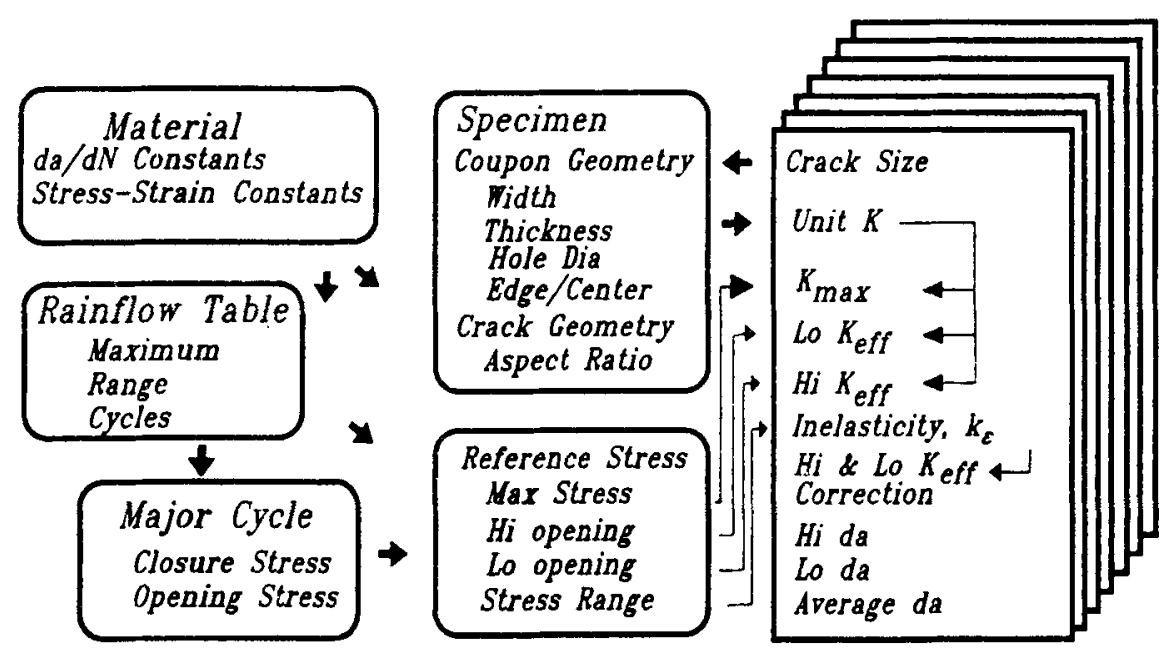

Figure 21. Framework of notch root fatigue crack growth rate analysis (Sunder et al 1993b) 
a)

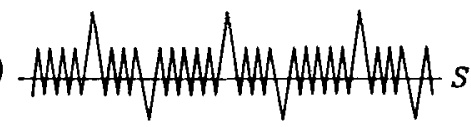

Applied stress

b)

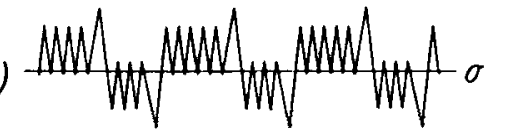

Notch root local stress

c)

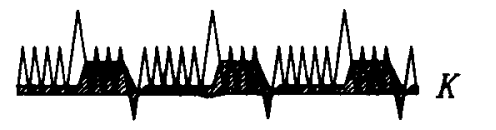

Notch root crack, inelastic

$S_{c l} \gg S_{o p}$

d)

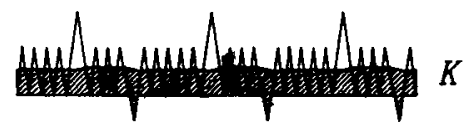

Long crack, elastic

$S_{c l} \sim S_{o p}$

Figure 22. Schematic of load interaction effects in crack initiation, short and long crack growth (Sunder 1991).

underloads superposed on a baseline sequence of small load cycles. If the notch root does not see inelastic strain under these stresses, notch root stress strain will see a scaled, but linear response, indicating total absence of load interaction effects. Figure $23 \mathrm{~b}$ shows notch root inelastic stress-strain response. The beneficial effect of overload is seen by way of reduced mean stress in the following small cycles, while the underloads are followed by increased local mean stress. This is the basis for the load history effects as simulated by the Manson-Coffin-Topper equations in the LCF/LSS method. Figure 23c shows crack closure response for a notch root crack. We find that as a consequence of crack closure hysteresis, fatigue damage due to crack growth is affected in much the same way as fatigue damage from LCF/LSS considerations in figure 23b. Finally, figure $23 \mathrm{~d}$ shows long crack elastic response, indicating little cycle-by-cycle sensitivity to load sequence. This observation may appear to contradict observations of retarded crack growth after an overload. It must be noted that the present discussion is restricted to cycle-by-cycle effects, while periodic overloads do introduce transient phenomena, with crack closure varying as the crack grows into and out of the overload plastic zone. Such transients are related to crack increment, rather than cycling and require due consideration in the event of large duration load spectra and high crack growth rates.

Considering that short cracks can initiate very early in life, it is indeed possible that much of what has been hitherto modelling effectively through LCF/LSS approach, may in fact fall within the framework of a fracture mechanics approach. The associated 'damage mechanics' concept was proposed by Newman et al (1992). However, the question of hysteresis in crack closure was not addressed in their work.

The crack closure concepts presented in the present paper and their extension to random load conditions through rainflow considerations has recently becn confirmed using high resolution laser interferometry studies of crack tip displacements under specially designed load sequences (Ashbaugh et al 1994). The study included a comprehensive finite element analysis of the problem which provided data that closely tie up with previous fractographic observations as well as the laser interferometry measurements. These 


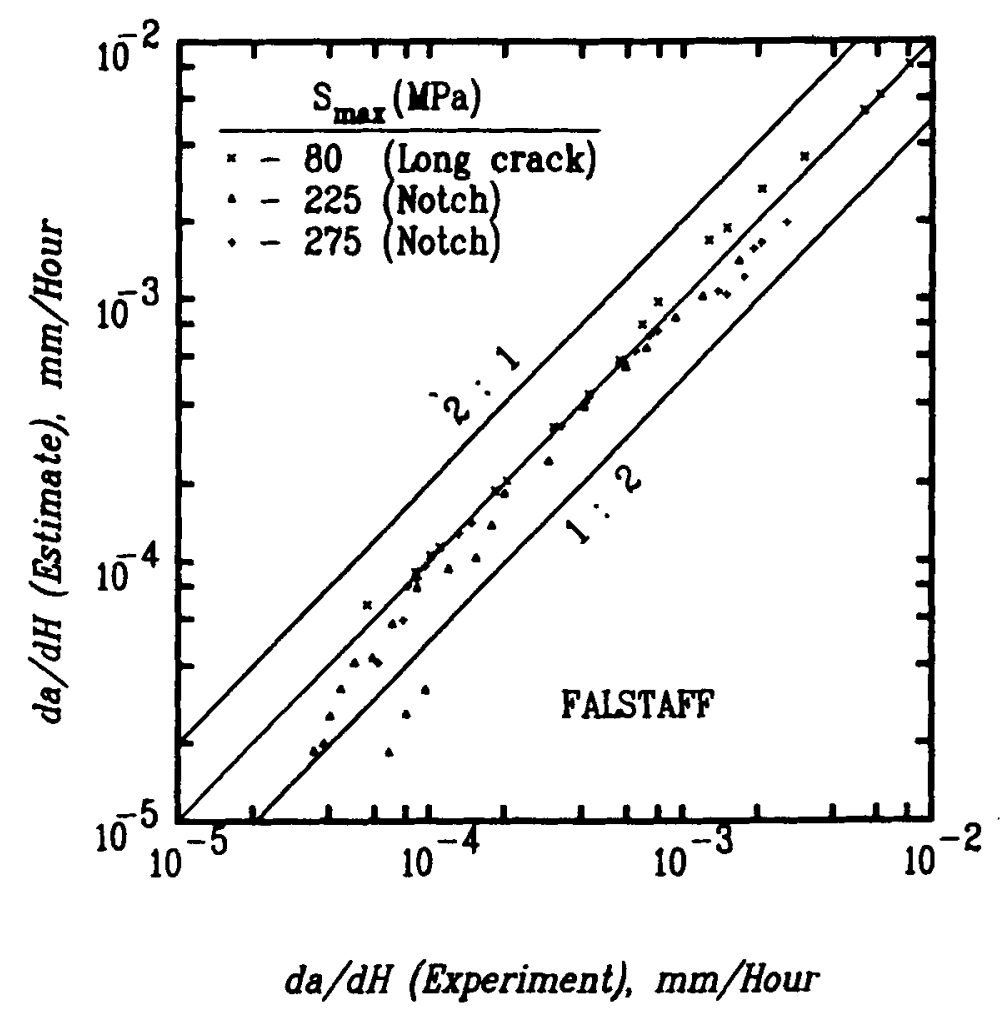

Figure 23. Summary of crack growth rate calculations for long and short cracks. Short crack data extend down to about 40 micron crack size (Sunder et al 1993b).

measurements were performed with reference to microscopic indents about 150 microns apart and about 50 to 100 microns ahead of the crack tip. Displacement over this gauge length versus applied load excursion is shown in figure 24 . Note that displacement is shown in relative terms as a deviation from the unloading load versus COD slope. The load sequence contains five rainflow counted cycles, two each on the rising and falling half of the major cycle. Clearly, $S_{\mathrm{op}}$ in the embedded cycles is greater than in the case of the major cycle as would also follow from the hysteretic closure model. The closure of the data loops also confirms earlier fractographic observations (Sunder et al 1984) on the validity of rainflow for fatigue crack growth. Finally, it appears to underline the relevance of energy balance considerations to fatigue damage through crack tip stress-strain hysteresis as explained in figure 4 (Raju 1980).

The preceding sections provide an indication about the value of fractography in understanding the nature of fatigue crack growth under complex loading. Described below is another application of quantitative fractography.

\section{Notch root short crack growth under spectrum loading}

The evaluation of short crack growth rate predictions under spectrum loading (figure 23) posed the requirement of obtaining reliable experimental data (down to 


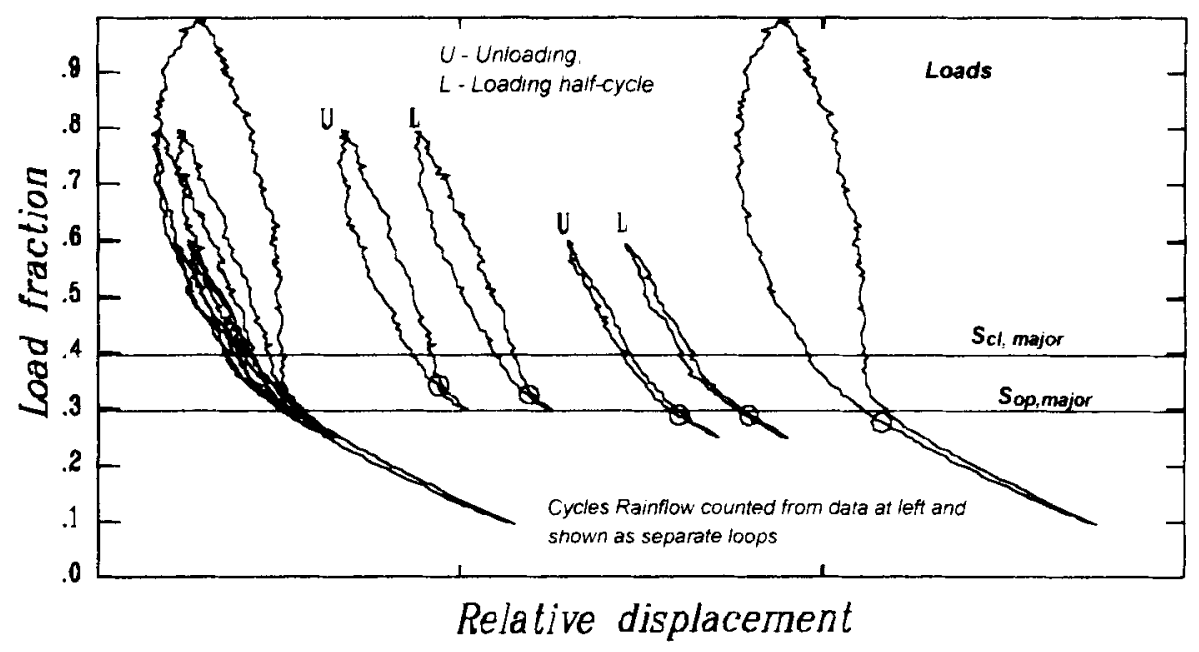

Figure 24. Relative crack opening displacement versus load in a complex sequence shown at top right. Data from laser interferometry over entire sequence shown at left. Small circles indicate Sop in individual counted cycles (Ashbaugh et al 1994).

crack size of under 50 microns) that could be used as a reference. As such cracks have to initiate naturally (artifically initiated cracks would have an unacceptably large initial size), they cannot be tracked by conventional instrumentation, particularly when multi-site initiation is possible. Available data from the literature have largely been obtained using surface replica technique (Newman \& Edwards 1988). In our studies, an attempt was made to characterize short crack growth rates through optical fractography.

The basis for fractographic crack growth rate estimation is the correlation between crack extension per cycle and striation spacing. Striations in turn can be due to a single cycle or due to a group of cycles. Figure 3 showed examples of both. The FALSTAFF load spectrum which was used in the study is a randomized load sequence. It was adapted for fractography by conversion into a programmed load sequence (Sunder $e t$ al 1993a). To ensure equivalence of the two, the sequence was first reduced to a rainflow cycle count. A total of 18 large cycles of different magnitude were identified in the spectrum. The remaining cycles were broken into 18 similar blocks. One each was attached to each one of the major cycles. Care was taken to space the two largest cycles apart in such a manner that they could be easily identified on the fracture surface. The resultant programmed load sequence (shown in figure 25 ) was checked for equivalence with the original FALSTAFF sequence, first analytically, then, after minor adjustments, experimentally, to ensure that the two sequences provided the same growth rates on a long crack that could be monitored visually, through instrumentation ( from unloading compliance) and fractographically (to ensure that fractographic estimates under programmed loading conform to visual observations). These results appear in figure 26.

The fractographically determined crack growth rate curve was integrated 'backwards from the failure point' down to the smallest possible crack size (ranging from 10 


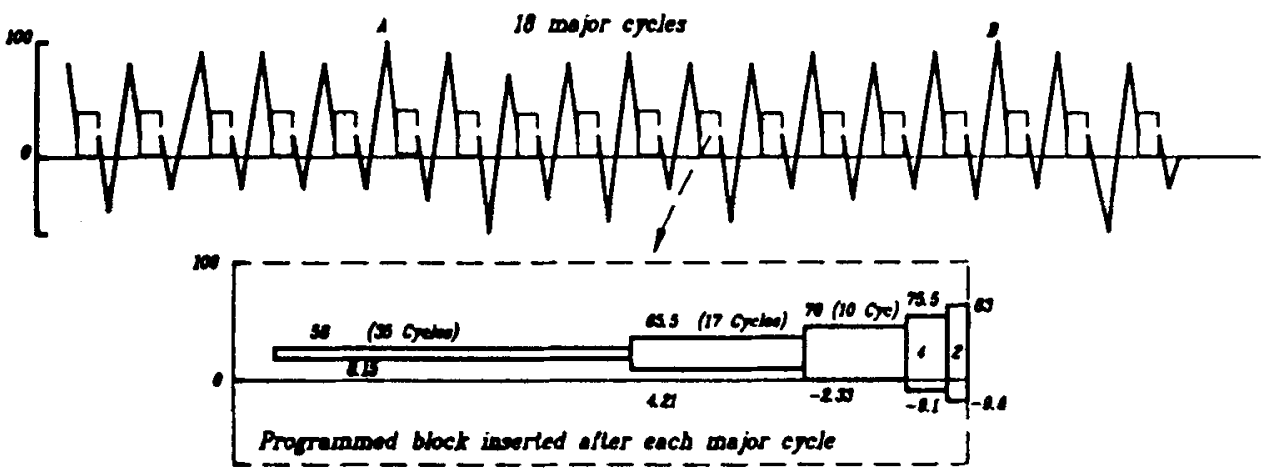

Figure 25. Programmed FALSTAFF load sequence used in fractographic studies on notch root crack growth (Sunder et al 1993a)

to 50 microns, depending on the clarity of pictures). This gave the crack propagation life. Life to formation of the small crack was then estimated as the difference between endurance and crack propagation life. As a consequence, the fractographic technique provided the opportunity to examine aspects of early crack growth that could not be addressed using conventional methods. This procedure was used in experiments on a number of notched coupons at different stress levels. Later, the same procedure was used to study crack growth in a lug joint, whose description is forthcoming.
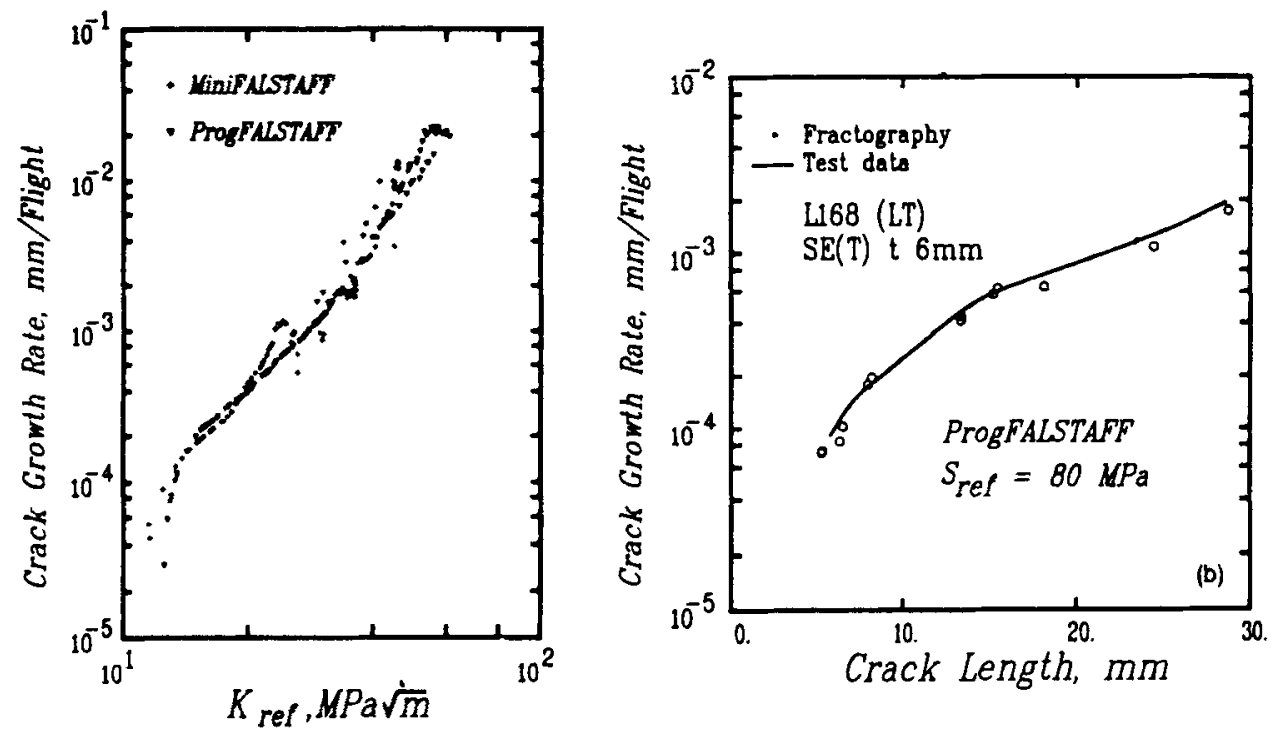

Figure 26. Long crack growth rates under randomized MiniFALSTAFF and programmed FALSTAFF (left), Fractographic and visual observations of crack growth rate under programmed FALSTAFF (right) (Sunder et al 1993a). 
The study provided many significant observations (Prakash et al 1994; Sunder et al 1994):

- Surface replica based measurements provide an exaggerated measure of scatter in growth rate. Short crack growth rates do not exhibit more scatter than long cracks at comparable growth rates. This is illustrated by the data in figure 27 . The scatter seen in replica based data is obviously related to shortcomings in the technique and also to the possibility that there indeed may be some discontinuity in crack extension as registered on the specimen surface.

- Number of naturally initiating cracks increases with applied stress level. Figure 28 summarizes this effect from tests on coupons of two thicknesses. These data are for the FALSTAFF spectrum. It is possible that the relationship will depend on the load spectrum under consideration as crack formation is likely to be accelerated by the larger cycles in the spectrum. In case of the TWIST spectrum, the larger cycle accounts for less damage as indicated by the RDE diagram in figure 7 . It would

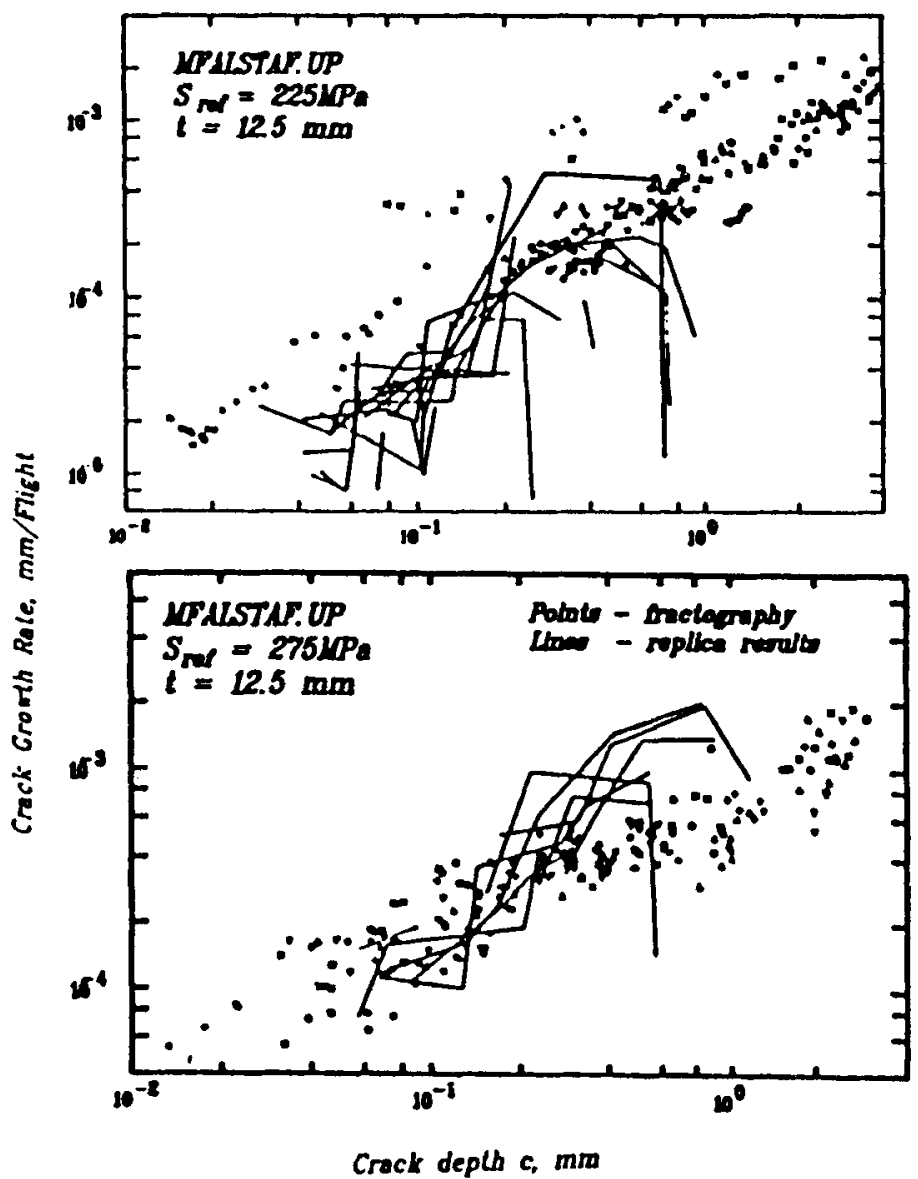

Figure 27. Replica and fractography based crack growth rate estimates for naturally initiating multiple cracks at two different stress levels (Sunder et al 1994). 


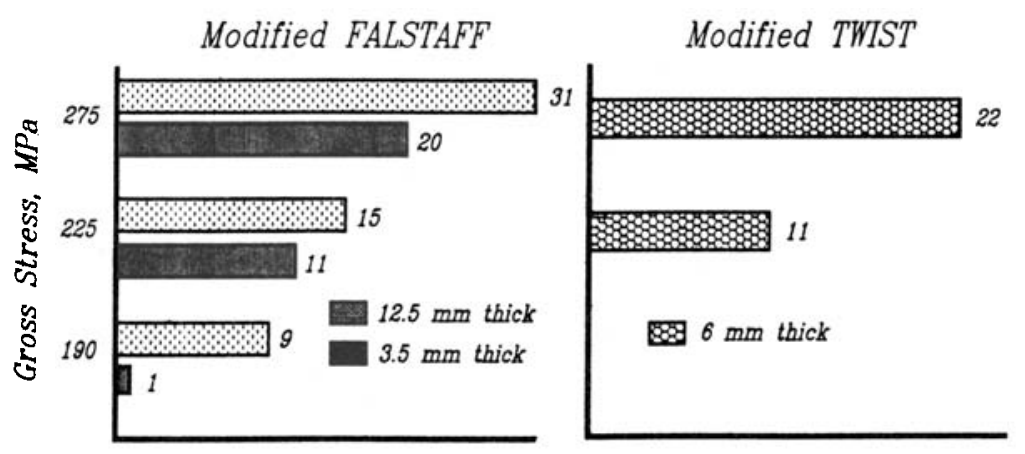

No. of Crack Initiators

Figure 28. Effect of stress level on number of crack initiating sites. Data for two different specimen thicknesses (Sunder \& Prakash 1994).

follow that in case of TWIST, fewer initiation sites will be associated with the same stress level when compared to FALSTAFF.

- Artificially initiated fatigue cracks behave differently from naturally initiating ones (see figure 29). Experiments on edge-notched coupons showed that naturallyinitiating cracks grow faster than artificially initiated ones. This was related to the crack initiator behaving as a blunt secondary notch inside the primary notch, when compared to a much sharper crack tip. It would follow that to be of practical value, short crack experiments must involve natural crack initiation.

- Multiple natural cracks do not initiate simultaneously. On the other hand, cracks that form early will accelerate the formation and growth of new cracks due to stress redistribution along the notch surface. This is illustrated by the results in figure 29 . Thus, the slowest crack on the fracture surface was possibly the dominant one, having formed earlier than the others. It was noted that for purpose of life calculations, consideration of the dominant crack alone is likely to provide satisfactory estimates.

\section{Fatigue crack growth in lugs under spectrum loading}

Advances in fracture mechanics and in our understanding of fatigue crack growth mechanisms have largely been based on laboratory testing of coupons with standard stress intensity solutions. Many fatigue failures on airframes occur at joints and fasteners, which represent a fairly complex geometry.

In a recent new application of fractography, lug joints with different degree of interference fit were tested to failure under both constant amplitude as well as programmed FALSTAFF loading conditions (Sunder $\&$ Prakash 1994). The fracture surface was then studied to determine growth rates down to crack size below 50 microns. The measurements were performed with an optical microscope equipped with digital imaging technology. The constant amplitude growth rates were then compared with data from standard laboratory coupons to derive a stress intensity calibration. These data appear in figure 30 . They appear to indicate shortcomings in available 
a)
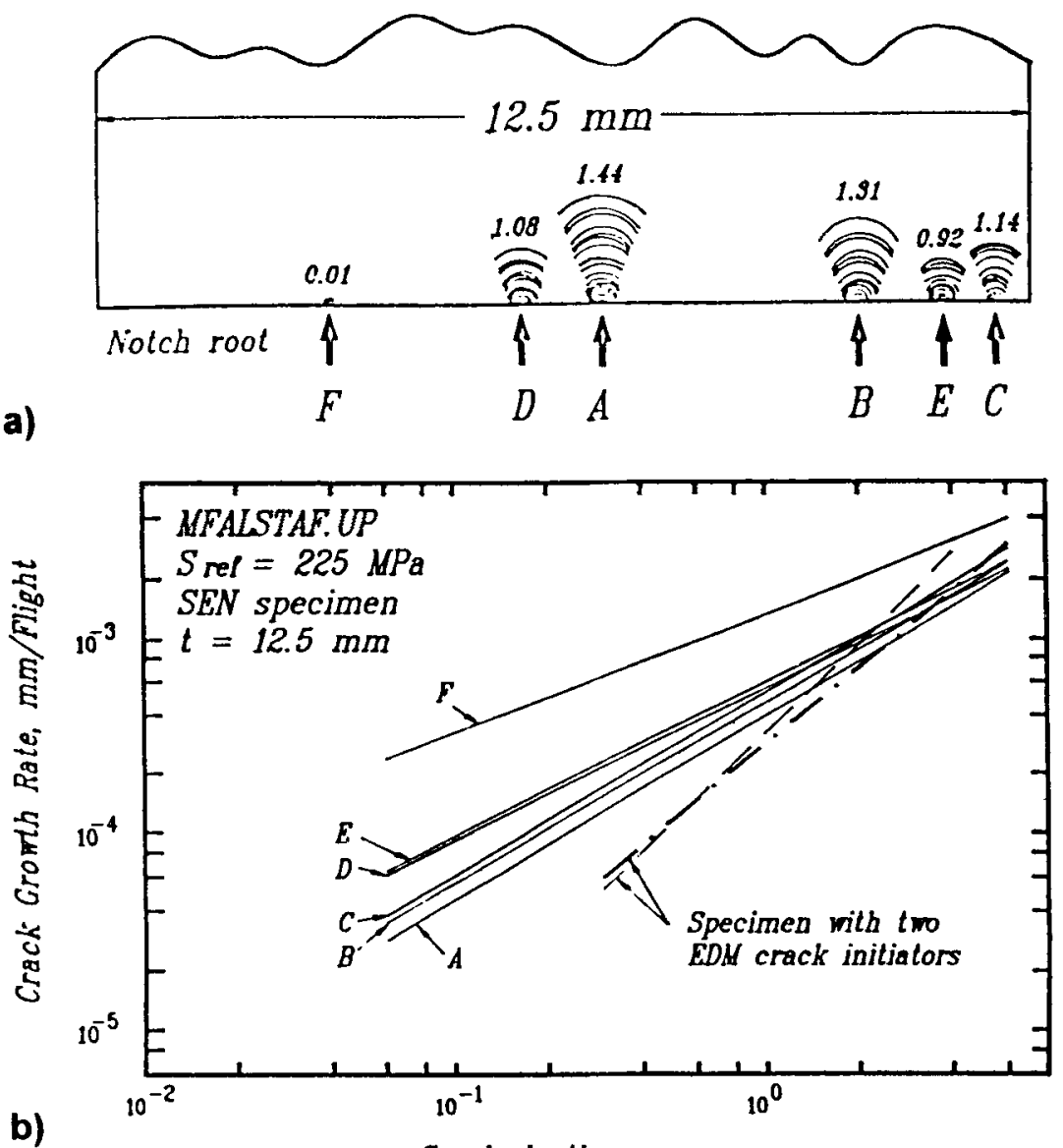

Crack depth c, mm

Figure 29. Reconstructed intermediate crack front mapping from multiple sites $A-F(a)$, and (b) crack growth rates for individual cracks. ' $A$ ' was the dominant crack having appeared first, while B-F exhibit accelerated growth rates. Two discontinuous lines in (b) show the lower growth rates for artificially initiated cracks (Sunder \& Prakash 1994).

analytical solutions for stress intensity in lugs, particularly when small cracks are involved (about 150 microns and less). On the other hand, the data also indicated that irrespective of the degree and nature of the interference fit, crack growth rate appear to fall into a single scatter band above a crack size of about 150 microns. While this observation requires verification for other stress levels, one may conclude that given a suitable stress intensity calibration, fracture mechanics can handie the durability as well as damage tolerance of joints and fasteners.

\section{Concluding remarks}

The research described in this paper was aimed at improving fatigue life prediction technology in engineering application. While the materials and load spectra studied are 


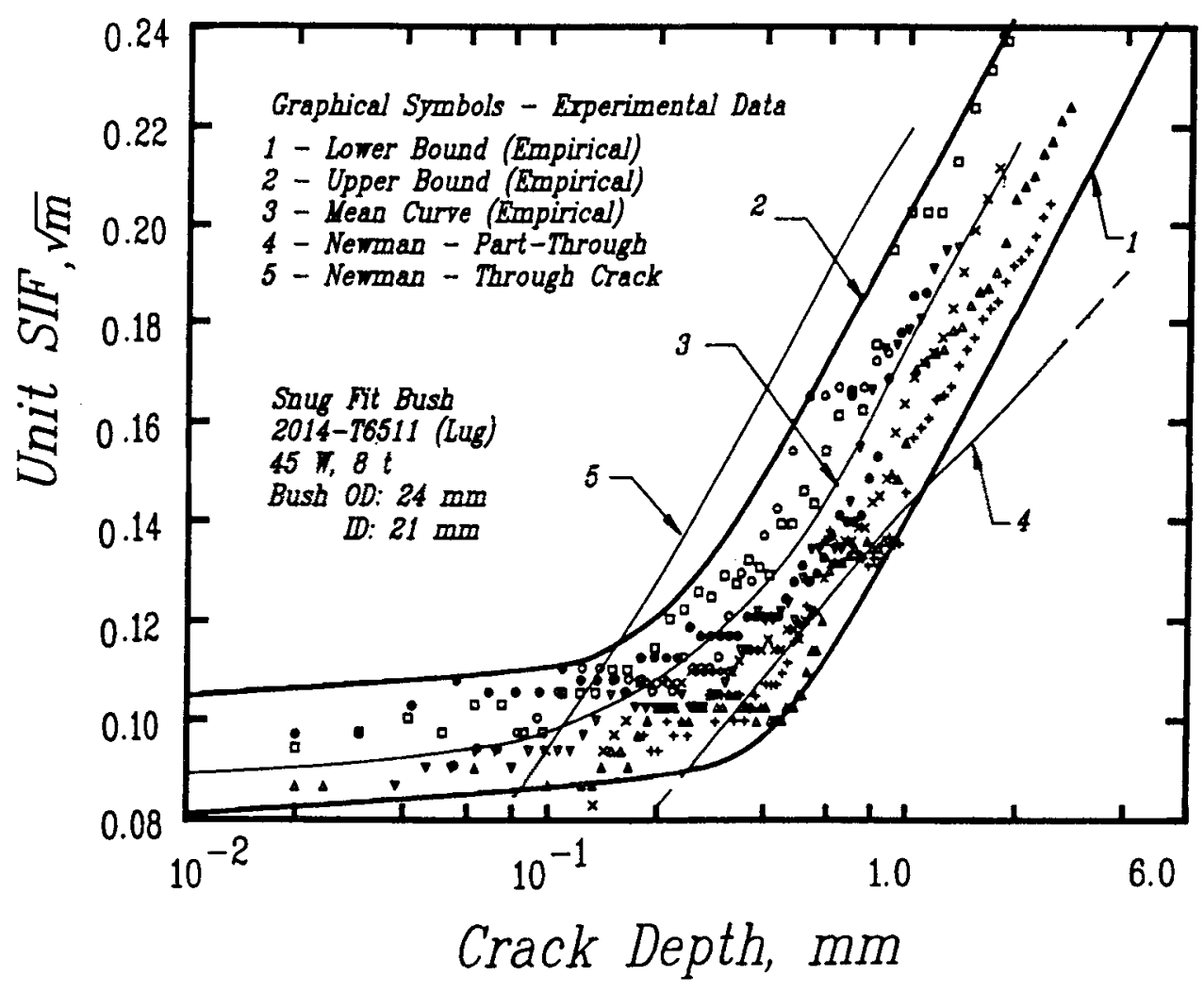

Figure 30. Calibrated stress intensity versus crack depth for a part-through crack growing out of the lug notch root. Calibration obtained under constant amplitude loading (Sunder \& Prakash 1994).

specific to airframe structural application, they may be relevant to many other fatigue critical structures and machinery. The complexity of metal fatigue in engineering application may be attributed to a number of factors, including:

- Stress distribution in a builtup structure, particularly at stress raisers and its response to dynamic loading conditions,

- cumulative damage under random load conditions, typical of service environrent, and,

- effects of environment, creep and residual stress variation that may change initially assumed mechanical properties and response.

The work described in this paper relates to the second aspect, which centres around the extrapolation of test data obtained on laboratory coupons under constant amplitude loading to real components subject to a random load environment:

- Difference between an arbitrary load sequence and constant amplitude loading from the viewpoint of cumulative damage.

The rainflow cycle counting technique bridges this difference. While it was discovered in a low-cycle fatigue framework, its validity for crack growth analysis 
has been demonstrated through electron fractography of failures obtained under specially designed programmed load sequences. In view of its mechanistic basis, the rainflow technique could be developed for accelerated fatigue life analysis and testing.

- Sensitivity of both crack initiation as well as crack propagation to load history (load interaction effects). Experience shows these can account for more than an order of magnitude variation in fatigue life.

Most life prediction models account for history effects by simulating the effect of mean stress. A hypothetical material, whose fatigue response is insensitive to mean stress, is also likely to be insensitive to load history effects. Fatigue crack closure has been identified as the means through which mean stress affects crack growth. The experimental research described in this paper provided a better understanding on crack closure distribution across the crack front in through as well as short, part-through cracks.

A significant outcome of recent research has been the discovery of hysteresis in fatigue crack closure. This discovery provides the link between fracture mechanics and low-cycle fatigue considerations of fatigue damage under complex loading and may lead to a unified consideration of the fatigue problem.

A central feature of the research described in the paper is its interdisciplinary approach. All the experiments involved specially designed loading that required extensive use of custom-built test automation. Computer controlled testing at NAL saw much progress over the past 15 years and the technology is currently being commercialized. Most experiments were followed up by electron and optical fractography, which in recent years has gained from the appearance of cost effective PC-based image enhancement and processing techniques.

Further work is recommended in the area of natural crack formation under service loading. While fracture mechanics appears to be able to handle cracks as small as 20 microns, high endurance applications (particularly engine components and automobile suspension) require better understanding of how a crack of that size forms - of course under a randomized load environment. The problem holds exciting avenues of research in the area of fasteners, which appear to often determine the quality of structural integrity assurance. Finally, load monitoring technology for built-up structures combined with NDE and life prediction technology have potential application in life extension schemes in view of aging problems and growing cost of new installations.

\section{Scope of analytical effort}

Analytical modeling in solid and fluid mechanics including fracture mechanics proceeds from first principles and basic material constants. Fatigue life prediction in contrast is essentially restricted to extrapolation of laboratory data obtained either under constant amplitude or random loading to other sequences, stress levels and crack geometries. Laboratory coupon level testing for data generation is therefore required for every new mateial and its variation including processing. National Aerospace Laboratories have been actively involved in material test data generation for design as well as type certification purposes. A few thousand tests have been performed over the past six years to determine the LCF and $\mathrm{FCP}$ constants for a variety of $\mathrm{Al}-\mathrm{Cu}, \mathrm{Al}-\mathrm{Li}$, steel and titanium alloys used in airframe applications. Such testing contributed to type 
approval of a number of indigenous materials for airframe materials and to the qualification of imported candidate materials for use in aircraft development programmes.

Stringent requirements on air worthiness and structural integrity require laboratory level full-scale testing to demonstrate the quality of a new design or modification of operating aircraft. All the preceding analyses including residual life predictions are intended to ensure a high degree of probability that the design as a total system will survive certification testing under conditions that closely simulate real operation over the stipulated service life. This concept is now followed by the highly competitive auto industry in view of the high costs of retrofits under warranty and liability clauses. In the years to come, it is likely that other industries in the country, including energy, chemical industries, rail transportation and consumer durable sector will follow the same trend. Thus, in the years to come, testing will continue to play a major role in qualifying the durability and damage tolerance of materials and structures, while analytical effort will be expected to optimize design and make testing more cost effective.

The work described in this paper enjoyed the strong support of Dr S R Valluri, Prof R Narasimha and Dr K N Raju. Financial support for the effort was provided by Aeronautical Research \& Development Board, Aeronautical Development Agency and Department of Science and Technology. The author would like to place on record the considerable effort of professional colleagues from many countries, who contributed by way of peer review and encouragement to the documentation in international literature of the reported research. The support over the years from colleagues from the Materials Science Division, Structures Division, Engineering Services and Graphic Arts at NAL is gratefully acknowledged. Finally, the author is indebted to colleagues in the Structural Integrity Division for their active involvement and unstinting support in the studies reported in this paper.

\section{References}

Anandan K, Sunder R 1987 Closure of part through cracks at the notch root. Int. J. Fatigue 9: $217-222$

Ashbaugh N E, Dattaguru B G, Khobeib M, Nicholas T, Prakash R V, Seshadri B, Sunder R 1994 Experimental and finite element study of crack closure Parts 1 \& 2.J. Fatigue Fracture Eng. Mater. Struct (submitted)

Christensen R H 1959 Metal fatigue (New York: McGraw-Hill)

Chang J B, Hudson C M (eds) 1981 Methods and models for predicting fatigue crack growth under spectrum loading. ASTM STP 748

de Koning A U 1981 A simple crack closure model for prediction of fatigue crack growth rates under variable amplitude loading. ASTM STP 743 pp. 384-412

Dougherty D J, de Koning A U, Hillberry B M 1992 Modeling high crack growth rate under variable amplitude loading. ASTM STP 1122 pp. 214=233.

Dowling N E, Brose W R, Wilson W K 1977 Notched member fatigue life predictions by the local strain approach. Fatigue under complex loading: Analyses and experiments (Warrendale, PA: Society of Automotive Engineers) vol. AE-6, pp. 55-84

Dowling N E, Khosrovaneh A K 1989 Simplified analysis of helicopter fatigue loading spectra ASTM STP 1006 pp. $150-171$

Elber W 1971 The significance of fatigue crack closure (Philadelphia: American Society for Testing and Materials) ASTM STP 486, p. 230 
Elber W 1976 Equivalent constant-amplitude concept for crack growth under spectrum loading. ASTM STP 595 pp. 236 250

Endo T, Mitsunaga K, Nakagawa H 1967 Fatigue of metals subjected to varying stress prediction of fatigue lives. Paper presented at Kyushu District Meeting of the Japanese Society of Mechanical Engineers, JSME, Kyushu

Lincoln J W, 1994 Overview of the structural integrity process, an assessment of fatigue damage and crack growth prediction techniques. AGARD Report 797, Paper LP

Manson S S, Freche J C, Ensign, C R 1966 Application of a double linear damage rule to cumulative fatigue. Fatigue crack propagation. ASTM STP 415, pp. 384-412

Miner M A 1945 Cumulative damage in fatigue Trans, ASME, J. Appl. Mech. 12: A159-164

Morrow J 1968 Fatigue properties of metals. Fatigue design handbook Soc. of Automotive Eng. $\$ 3 \cdot 2$

Neuber H 1961 Theory of stress concentration for shear-strained prismatical bodies with arbitrary nonlinear stress-strain law. Trans. ASME, J. Appl. Mech. 28: 544-550

Newman J C 1981 A crack closure model for predicting fatigue crack growth under aircraft spectrum loading. ASTM STP $748 \mathrm{pp}$. 53-84

Newman J C, Edwards P R 1988 Short crack growth behaviour in an aluminum alloy - An AGARD cooperative test programme. AGARD Report 732

Newman J C Jr, Phillips E P, Swain M H, Everett R A Jr, 1992 Fatigue mechanics: An assessment of a unified approach to life prediction. Advances in fatigue lifetime predictive techniques (eds) M R Michell, R W Landgraf, ASTM STP 1122 pp. 5-27

Pelloux R M N, Faral M, McGee W M 1980 Fractographic measurements of crack tip closure. Fracture Mechanics: Twelfth Conf. ASTM STP 700, pp. 35-48

Poe C C 1971 Fatigue crack propagation in stiffened panels. ASTM STP 486, pp. 79-97

Prakash R V, Sunder R, Mitchenko E 11994 A study of naturally initiating notch root fatigue cracks under spectrum loading. NAL Project Document SN 9406. National Aerospace Laboratories Bangalore

Raju K N 1980 Energy balance considerations in ductile fracture and fatigue crack growth, $\mathrm{PhD}$ thesis, Indian Institute of Science, Bangalore

Ritchie R O, Suresh S 1982 Some considerations on fatigue crack closure induced by fatigue fracture morphology. Metall. Trans A13: 937-940

Schijve J 1967 Significance of fatigue cracks in micro-range and macro-range. Fatigue crack propagation. ASTM STP 415, pp. 415-459

Schijve J 1974 Fatigue damage accumulation and incompatible crack front orientation Eng. Fracture Mech. 6: 245-252

Schijve J 1979 Prediction methods for fatigue crack growth in aitcraft material. Report LR-282, Delft University of Technology, Delft

Schuetz W 1989 Standardised stress-time histories - An overview. (eds) J M Potter, R T Watanabe, ASTM STP 1006, pp. 3-16

Sunder R 1983 Binary coded event registration on fatigue fracture surfaces. Proc. SEECO'83 (ed) B Dabell (London: Society of Environmental Engineers) p. 197

Sunder R 1985 System for automated crack growth testing under random loading. Int. $J$. Fatigue 7: 3-12

Sunder R 1989 Compilation of procedures for fatigue crack propagation testing under complex load sequences. (eds) J M Potter R T Watanabe, ASTM STP 1006 pp. 211-230

Sunder R 1991 Notch root crack closure under cyclic inelasticity. Project Document PDST 9132 National Aeronautical Laboratory (Also 1993 J. Fatigue Fracture Eng. Mater. Struct.) 16: $677-692$

Sunder R 1992a Rainflow applications in accelerated cumulative fatigue analysis. The rainflow method in fatigue (eds) Y Murakami (Oxford: Butterworth Heinemann) pp. 67-76

Sunder R 1992b Near-threshold fatigue crack growth prediction under spectrum loading (eds) M R Mitchell, R W Landgraf, pp. 161-175

Sunder R 1992c Contribution of individual load cycles to crack growth under aircraft spectrum loading (eds) M R Mitchell, R W Landgraf, ASTM STP 1122, pp. 176-190

Sunder $R 1993$ Contribution of individual spectrum load cycles to damage in notch root crack initiation. Short and long crack growth (eds) M R Mitchell, R W Landgraf, ASTM STP 1211, pp. 19-29 
Sunder R, Dash P K 1982 Measurement of fatigue crack closure through electron microscopy. Int. J. Fatigue 4: 97-105

Sunder R, Prakash R V 1994 A study of fatigue crack growth in lugs under spectrum loading. Project Document SN 9407. National Aerospace Laboratories Bangalore (submitted for publication in ASTM STP).

Sunder R, Prakash R V, Mitchenko E I 1993a Fractographic study of notch fatigue crack closure and growth rates (eds) J E Masters, L N Gilbertson, ASTM STP 1203 pp. 113 131

Sunder R, Prakash R V, Mitchenko E I 1993b Calculation of spectrum load notch root crack growth rate under elastic and inelastic conditions. (eds) M R Mitchell, $R$ W Landgraf (Philadelphia: American Society for Testing and Materials) ASTM STP 1211, pp. 30-44

Sunder R, Prakash R V, Mitchenko E I 1994 Growth of artificially and naturally initiating notch root cracks under FALSTAFF spectrum loading. AGARD Report 797, Paper 10

Sunder R, Seetharam S A, Bhaskaran T 1984 Cycle counting for fatigue crack growth analysis. Int. J. Fatigue 6: 147-156

Sunder R, Venkatesh C S 1990 Dedicated microprocessor based controller for fatigue testing. (eds) A A Braun, N E Ashbaugh, F M Smith. ASTM STP 1092, pp. 68-82

Suresh S, Ritchie R O 1982 A geometric model for fatigue crack closure induced by fracture surface roughness. Metall. Trans

Suresh S, Zamiski G F, Ritchie R O 1981 Oxide induced crack closure: An explanation for near threshold corrosion fatigue crack growth behavior. Metall. Trans., A12: 1435-1443

Topper T H, Sandor B I 1970 Effects of mean stress and prestrain on fatigue damage summation. Effects of environment and complex load history on fatigue life ASTM STP 462, pp. 93-104

Vormwald M, Heuler P, Seeger T 1992 A fracture mechanics based model for cumulative damage assessment as part of fatigue life prediction. ASTM STP 1122, pp. 28-43

Wetzel R M 1971 A method for fatigue damage analysis. Ph D thesis, Department of Civil Engineering, Univ. of Waterloo, Ontario

Zuidema J, Blaauw H S 1988 Slant fatigue crack growth in Al-2024 sheet material. Eng. Fracture Mech. 29: 401--413 